\title{
Pragmatismo reformista, pragmatismo radical. Respuesta a "Viejo y nuevo pragmatismo" de Susan Haack*
}

\author{
RAMÓN DEL CASTILLO \\ Departamento de Filosofía \\ Universidad Nacional a Distancia \\ rcastillo@fsof.uned.es
}

\begin{abstract}
Resumen: En Diánoia 47, Susan Haack presenta un trabajo en el que repasa la historia del pragmatismo, proponiendo una división general entre pragmatistas reformistas y pragmatistas radicales. En este trabajo intento discutir algunas de sus propuestas y criticar cierto sesgo antihistoricista de su enfoque, centrado principalmente en la epistemología. Repaso algunas ideas de James, Dewey y Quine, y explico por qué Haack tiene problemas para llevarlos hacia las filas del reformismo. Dado que Haack asocia a Richard Rorty con un nuevo pragmatismo radical contraproducente, mostraré cómo Rorty puede sentirse a la vez un convencido moderado en temas sociales y políticos, mientras que pasa por radical en temas de epistemología. Después de todo, la cuestión última es: ¿influyen realmente las teorías epistemológicas en los debates culturales?
\end{abstract}

Palabras clave: crítica cultural, epistemología, historia del pragmatismo

Antes de nada, debería empezar manifestando mi respeto por las ideas de Haack, ideas que, de una forma u otra, siempre han influido en quienes nos hemos dedicado a discutir temas relacionados con el pragmatismo americano. En mi propio caso, Evidence and Inquiry $(1993)^{1}$ me dio mucho que pensar, aunque, curiosamente, la dirección hacia la que Haack me empujó fue distinta, e incluso contraria, a la que ella misma tomaba. Entre los méritos de Haack, pues, yo incluiría el de generar debate y considerar los argumentos contrarios, en vez de encerrarse en sí misma o hacer escuela. Su actitud hacia el legado del pragmatismo americano es, diría yo, polémica, una actitud gracias a la cual viejas ideas (principalmente las de Peirce, su héroe pragmatista predilecto) adquieren un significado renovado en el contexto de los debates contemporáneos, tal como puso de manifiesto su siguiente y estupendo libro, Manifesto of a Passionate Moderate (1998), libro que seguramente dará que hablar cuando aparezca en castellano y que demuestra sin ningún género de dudas que Haack sabe conectar como nadie el viejo y el nuevo pragmatismo (véase, si no, el ingenioso diálogo

\footnotetext{
*S. Haack, "Viejo y nuevo pragmatismo", Diánoia, vol. XLVI, no. 47, pp. 21-59.

${ }^{1}$ Me referiré en adelante a la versión en castellano: Evidencia e investigación, Tecnos, Madrid, 1997.
} 
que inventa entre la vieja y la nueva guardia en "We pragmatists. .. : Peirce and Rorty in Conversation").

No me gustaría dar a entender, por tanto, que lo que voy a decir aquí sobre su ensayo publicado en Diánoia sea una crítica total a su postura. La visión que Haack tiene del pragmatismo clásico y del neopragmatismo no se debería juzgar exclusivamente a través de lo que dice en "Viejo y nuevo pragmatismo". Creo que otros trabajos suyos aclaran más lo que en este caso ella plantea de una forma quizás demasiado divulgativa. No obstante, la divulgación no está reñida con la polémica y está claro que Haack también aprovecha este tipo de trabajos para lanzar algunos argumentos de peso. "Viejo y nuevo pragmatismo" es, sin duda, una visión de conjunto de una tradición intelectual con cierto tono propagandístico, una visión que contrarreste los, a su juicio, excesos de otras sectas neopragmatistas.

\section{Presentación}

La primera idea que me llama la atención es la de un pragmatismo de estilo reformista que Haack identifica con el espíritu originario del movimiento, o más exactamente, con las intenciones del padre fundador del pragmatismo: Peirce. Según Haack, Peirce no renunció a las aspiraciones de la Filosofía (con mayúscula), siempre que fuera una filosofía reformada a través de una actitud científica, una filosofía que enfocara las viejas e interminables disputas filosóficas y metafísicas con un tono experimental, pero que no delegara las cuestiones filosóficas a las ciencias naturales ("Viejo y nuevo pragmatismo", p. 22, a partir de ahora, citaré el artículo como VNP). En este punto, creo, Haack tiene toda la razón, o sea, Peirce pensaba así, aunque la idea de "reformismo" suaviza los delirios de grandeza de Peirce y sus obsesiones por una nueva Filosofía (también con mayúscula) que reinara sobre el conjunto del saber. La propia obra de Haack podría entenderse como una demostración de que se puede seguir pensado con espíritu peirceano sin esos excesos y, por tanto, es razonable que promocione la faceta más moderada de Peirce.

Sea como sea, la idea más polémica de Haack es que la historia del pragmatismo consiste en una, llamémosla, distorsión de este pragmatismo originario, peirceano y reformista. A lo largo del tiempo — dice ella—, el pragmatismo reformista clásico se ha ido transmutando, para mal, en un neopragmatismo "revolucionario" o "radical" (VNP, p. 49) que fomenta modas relativistas y posmodernas, aunque Haack también insinúa que en el pragmatismo clásico (en James y Schiller, sobre todo) ya había gérmenes o antecedentes de ese radicalismo (luego volveré sobre esto). 


\section{A vueltas con los radicales}

Hasta donde sé, Haack ya había utilizado anteriormente esta distinción entre pragmatismo reformista y revolucionario (o radical); más exactamente, en la voz "Pragmatism" para A Companion to Epistemology que coordinaron Dancy y Sosa en $1992 .^{2}$ El significado de "radical", además, parece solaparse con el de "vulgar" tal como lo usó en Evidencia e investigación (cap. 9: "Pragmatismo vulgar: una perspectiva nada edificante").

En cualquiera de los casos, ni "radical" ni "vulgar" son elogios, sino más bien lo contrario: cierta acusación de rudeza, de irresponsabilidad, de irreverencia. Después de todo, los reformistas de Haack quizás vuelvan a encarnar algo de lo que James llamó tender-minded, mientras que los radicales son los nuevos ejemplos de un tough-minded. Haack, desde luego, diría que no, que los reformistas de hoy día no son la clase de racionalistas metafísicos y dogmáticos que James asociaba con un espíritu o carácter selecto (después de todo, los reformistas son pragmatistas, no se olvide). Y quizás los radicales de hoy día, habría que añadir, tampoco son los empiristas y materialistas escépticos de los que James también quería huir. Y sin embargo, pese a todas las diferencias, la vieja y legendaria distinción de James parece cubrir algo de lo que Haack se trae entre manos cuando divide a los propios pragmatistas en reformistas y radicales; los primeros, deseosos de conservar algunos principios, normas u objetivos últimos; los otros, de actitud más amoldable y flexible, volcados hacia las contingencias y menos pendientes de objetivos generales, demasiado abstractos y vacíos de contenido.

Según explicó Haack en "Pragmatism", la distinción entre el estilo reformista y el radical, introducida originalmente por M. Migotti en 1988, sirve para subrayar dos formas de hacer teoría del conocimiento que tienen en común una misma actitud crítica hacia la teoría clásica del conocimiento y que, desde luego, insisten en la conexión entre conocimiento y acción, pero que adoptan dos posturas muy distintas:

El pragmatismo de estirpe reformista [...] reconoce la legitimidad de las cuestiones tradicionales sobre la verdad como un objetivo esencial para nuestro conocimiento [on the truth-conductiveness of our cognitive practices] y sostiene una concepción de la verdad objetiva suficiente para que esas cuestiones tengan peso [enough to give that questions bite]. El pragmatismo de estirpe revolucionaria, en cambio, rechaza la objetividad de la verdad, y no reconoce la legitimidad de cuestiones epistemológicas que pretendan estar por encima [over and above] de las cuestiones inherentes a nuestras convenciones cognitivas habituales. ${ }^{3}$

${ }^{2}$ Agradezco a Ángel Faerna que me haya descubierto este texto de Haack cuando le hablé de la distinción entre pragmatismo radical y reformista.

3 "Pragmatism", p. 351. 
La posición radical o revolucionaria más peligrosa, asociada siempre a la figura de Rorty, vuelve a describirse más adelante en términos igual de taxativos. Para Rorty, dice Haack, el pragmatismo sostiene

que la verdad no es la clase de cosa sobre la que pueda haber teorías interesantes; que no hay nada que decir sobre los criterios de una creencia racional o sobre qué cuenta como prueba aceptable o como prueba insuficiente [good or flimsy] que esté por encima de las convenciones de nuestras prácticas cognitivas; concibe el pragmatismo como una repudiación revolucionaria de las preguntas, así como de las respuestas, asociadas a la tradición epistemológica. ${ }^{4}$

Siguiendo esta distinción que Haack vuelve a utilizar en el artículo de Diánoia, la historia del pragmatismo queda organizada no en dos, sino en tres grupos: reformistas, radicales y un grupo a medio camino entre ambos extremos.

Si comparamos "Viejo y nuevo pragmatismo" con "Pragmatism", el primer grupo de Haack, el reformista, lo formarían Peirce, Lewis, Mead, Sellars y ella misma, Haack. El grupo radical, en cambio, gente tan distinta como Schiller (el aliado inglés de James), Rorty, Stich o Churchland. ${ }^{5} \mathrm{Y}$ finalmente, el grupo intermedio, el grupo que tiene elementos reformistas $y$ radicales, incluiría a James, Dewey, Quine y Putnam, un grupo que, sin

${ }^{4}$ Ibid., p. 355.

${ }^{5}$ En Evidencia e investigación, Haack presentó a Rorty y a Stich como ejemplos del pragmatismo "vulgar". Ahora en "Viejo y nuevo pragmatismo" dice: "Antes de que Churchland abordara el tema, Rorty (junto con Feyerabend) había defendido el materialismo eliminacionista" (p. 49). ¿Habría que añadir a Feyerabend, por alusiones, como simpatizante del pragmatismo radical? Yo siempre lo he creído así. Baste está declaración suya, en respuesta a la dichosa pregunta de ¿qué es la verdad?: "Pues, unas veces una cosa y otras otra. ¿Cree usted realmente que hay una explicación breve que le satisfaga y que contenga todas las maneras en que uso el término 'verdadero'? O, más generalmente, ¿que hay algo que puede explicar por qué la gente dice que la teoría del Big Bang es verdadera, la existencia de Dios es verdadera, el sufrimiento de Cristo es verdadero, la maldad de mi suegra es verdadera y que es verdad que tengo hambre en este mismo momento? ¿Supone usted que en todos estos casos queremos decir la misma cosa y que podemos explicar esta cosa con una o dos frases? Se supone que delante de un juez un testigo dice la verdad, toda la verdad y nada más que la verdad. Compare esto con la Verdad del cristianismo. La primera tiene que ver con detalles, la segunda con toda la historia de la humanidad. Naturalmente, se trata de la misma palabra, pero eso no implica que tenga el mismo sentido, o algún sentido en absoluto" (Ambigüedady armonía, p. 154). Feyerabend dijo también algo que viene al caso y que, creo yo, difícilmente no lo suscribirían James o Dewey: "Que el recurso a la verdad y la racionalidad es tan retórico como desprovisto de contenido objetivo resulta evidente si se tiene en cuenta lo escasamente articulada que está su defensa [...]; la pregunta '¿qué ventajas tiene la ciencia?' apenas se plantea y no se le da una respuesta satisfactoria. Lo mismo puede decirse de otros conceptos fundamentales. Los filósofos investigan la naturaleza de la verdad, o la naturaleza del conocimiento, pero rara vez se preguntan por qué ha de buscarse la verdad (la pregunta sólo se plantea en la frontera entre las tradiciones: se planteó, por ejemplo, en la frontera entre la ciencia y el cristianismo)" (La ciencia en una sociedad libre, p. 95). 
duda, Haack siempre se esfuerza por incorporar a las filas de los pragmatistas reformistas. ${ }^{6}$ Lo importante de todo, creo, es que Haack sólo explica superficialmente por qué no es fácil domesticar a este grupo intermedio. Consideremos, al menos, cuatro casos: James, Dewey, Quine y Putnam. ${ }^{7}$

En el caso de James, ella siempre trata de dar una imagen muy moderada, eliminando su lado más cáustico y subrayando su lado constructivo, sobre todo en lo relativo al concepto de verdad. ${ }^{8}$ Pero James no se deja asimilar así como así, y Haack se ve obligada a admitir su faceta eliminacionista y radical, su énfasis en el proceso de fijación de creencias verdaderas, en plural, en vez de en la búsqueda de la verdad (VNP, p. 36).

Las dos amenazas radicales que subsisten en James son: nominalismo y enfoque psicológico, dos propensiones de James contra las que Peirce ya marcó distancias y que, desde luego, tampoco son bien vistas por Haack. Y con razón: después de todo, quizás James fue el primero en sugerir que es más mucho más fácil decidir qué es verdad en un caso concreto que decidir qué es la verdad; o que existe mucho más acuerdo en torno a qué son las verdades y cómo las aceptamos que a propósito de las dichosas teorías de la verdad. Como James dijo en un pasaje poco citado de Pragmatismo:

a la mayoría nunca se nos ocurre [...] que la cuestión de "qué es la verdad" no es una cuestión real (ya que no es relativa a condición alguna) y que toda esa noción de la verdad es una abstracción obtenida a partir del hecho de las verdades en plural, o sea, una simple expresión sumaria y útil como el latín, o la ley. ${ }^{9}$

${ }^{6}$ Véase "Pragmatism", p. 356, y compárese con "Viejo y nuevo pragmatismo", pp. 48 y ss.

${ }^{7}$ La clasificación de Haack, todo sea dicho, incluye a muchos otros personajes, pero no voy a aludir a ellos para hacer más simple la discusión. Por ejemplo, entre las filas reformistas también incluye a Lewis, Ramsey, Mead, Sellars, Rescher, Apel, Habermas; y, entre los que están a medio camino, también figuran Margolis y Bernstein. Apenas menciona, por cierto, a Morton White, pese a que Putnam lo ha defendido como la mejor alternativa al radicalismo de Quine. Tampoco menciona a Sidney Hook (excepto de pasada en la p. 46), pese a que Rorty lo considera el verdadero eslabón perdido del pragmatismo. Por lo que respecta a los simpatizantes del pragmatismo, ¿por qué no aludir a Christopher Hookway, un defensor de Peirce mucho más eficaz y persuasivo, creo yo, que Haack?, ¿y qué de las aproximaciones de Larry Laudan al pragmatismo? Con todo, sería algo injusto reprochar a Haack que no fotografíe a todo el mundo, dado que su propósito es algo divulgativo y, por tanto, la foto es un poco rápida.

${ }^{8}$ Compárese, si no, lo que dice en "Viejo y nuevo pragmatismo" con Evidencia e investigación, p. 276; "Pragmatism", p. 354 y ss., y el artículo "Can James's Theory of Truth be Made More Satisfactory?" Agradezco también a Ángel Faerna que me recordara y me facilitara la lectura de este trabajo de Haack.

${ }^{9}$ Pragmatismo, p. 195. El modo en el que surge una pregunta real por la verdad de una creencia (o conjunto de creencias) es un modo interrogativo y relativo a una situación particular. Una cosa es preguntar y contestar si es verdad esto o lo otro, y otra muy distinta preguntar y contestar qué es la verdad, pregunta que —como dice James en inglés_ es "irrelative to all conditions". Trátese, por lo demás, de imaginar una situación real, un verdadero problema, que pudiera suscitar en nosotros la pregunta: “¿qué es la verdad?” Y aunque llegáramos a 
Ciertamente, si uno empieza diciendo estas cosas, puede acabar diciendo cosas como que la gente debería preocuparse por obtener verdades y olvidarse de las teorías sobre la verdad, o cosas como que aquello que nos hace afirmar una creencia es lo mismo que nos hace afirmar que es verdadera.

Rorty, creo yo, sigue de cerca a James cuando dice que "verdadero" es un término de alabanza que pegamos a las creencias que, o de momento consideramos suficientemente justificadas, o que en un momento dado podrían llegar a justificarse, de forma que nada se puede decir sobre la verdad excepto que cada uno de nosotros calificará como verdaderas aquellas creencias que considere bueno creer. ${ }^{10}$ "Bueno", habría que decir, por razones específicas y concretas, bueno según el tipo de creencias y en relación con las condiciones que impone el problema al que responde cada creencia. Predicar verdad de una creencia, dice Rorty con jerga jamesiana, es como firmar un pagaré [a promissory note to get it cashed].$^{11} \mathrm{O}$ sea, nos comprometemos a dar explicaciones concretas, reales, de por qué aceptamos esa creencia. Por supuesto, nuestro sistema de justificación es un inmenso sistema de crédito - James lo explica muy bien en Pragmatismo-, pero el sistema tampoco funcionaría si flotara totalmente en el aire, sin ningún respaldo en efectivo. De igual modo, no todas nuestras predicaciones de verdad se pueden cobrar inmediatamente en líquido, pero hay una conexión, por indirecta y global que sea, entre predicar verdad de las creencias y su traducción en algo efectivo, en consecuencias, resultado o hechos que las convierten o las podrían convertir en conocimientos útiles, provechosos o ventajosos con relación a una serie de situaciones concretas. Cuando decimos cosas como "halló el camino correcto porque su creencia era verdadera", no estamos dando ninguna explicación, sino firmando un pagaré por verdaderas explicaciones, explicaciones del tipo "halló el camino correcto porque creía que..." Las explicaciones del éxito o fracaso, pues, las dan los detalles sobre lo que resultó verdadero o falso, y no la verdad o la falsedad en sí mismas, de la misma forma - dice Rorty- que lo que explica el carácter moral de una acción no es que era "lo correcto", sino los detalles de las circunstancias en los que se realizó esa acción. ${ }^{12}$

formularla..., ¿̇qué clase de respuesta a esa pregunta podría ayudarnos a entender y resolver conflictos reales como el choque de creencias religiosas, o entre creencias religiosas y científicas? (Véase sobre esto: R. del Castillo, “iA quién le importa la verdad? A vueltas con James y Dewey"). Obsérvese también lo que James dice en este pasaje de The Meaning of Truth: "La verdad en singular sólo es un nombre colectivo para las verdades en plural, que siempre consisten en series de sucesos específicos, y lo que los intelectualistas llaman la verdad, la verdad inherente a cualquiera de esas series, sólo es el nombre abstracto para referirse a la fiabilidad que tienen de hecho [truthfulness in act]; para referirse al hecho de que las ideas conducirán a la supuesta realidad de una manera que consideramos satisfactoria" (p. 109).

10 "Solidaridad u objetividad", pp. 42 y ss.

11 "Pragmatism, Davidson and Truth", p. 191.

${ }^{12}$ Ibid., p. 140. Creo que esto es una forma coherente de casar a Rorty con los pragmatistas 
Son estas justificaciones detalladas y no la verdad misma lo que explica por qué las creencias nos resultan satisfactorias, provechosas, adecuadas, correctas en relación con el problema que queríamos resolver. Como decía Sidney Hook, el hecho de que para calificar una creencia de verdadera sean necesarias una, dos o cientos de explicaciones es algo que depende de la clase de situaciones a las que la creencia trata de hacer frente; o sea, depende de la clase de problema y de la historia de los esfuerzos humanos por solucionar problemas similares. Sobre esto no hay ninguna teoría de la verdad que nos pueda decir nada, sino sólo la experiencia de que dispongamos y la que logremos adquirir.

El caso de Dewey (me atrevo a decir que el pragmatista menos estudiado por Haack en sus libros) también parece desesperarle un poco: "gran parte de sus escritos [de Dewey] parecen ambivalentes entre lo más y lo menos radical" —dice irónicamente (VNP, p. 39; compárese con Evidencia e investigación, p. 277, n. 21). Desde luego, también hay formas de arrimar a Dewey al radicalismo, no sé si hasta el punto radical al que aspira Rorty, pero sí hasta un punto más que sensato. El pragmatismo nos permite ver la búsqueda de la verdad como una especie o ejemplo de la búsqueda humana general de relaciones satisfactorias con el mundo. Cuando James dijo que lo verdadero es una especie de lo bueno — decía Dewey-, lo único que subrayaba es que para el punto de vista común y cotidiano, la verdad es un resultado empírico, un valor que adquieren las creencias de forma empírica, práctica, a través de su aplicación a lo largo de la experiencia. ${ }^{13}$

clásicos, pero el propio Rorty es más severo con ellos, y les reprocha no ser lo suficientemente eliminacionistas. James y Dewey, dice él, no se contentaron con desinflar el concepto de verdad, y trataron de dar algún contenido nuevo a la idea de correspondencia. Véase sus críticas a la noción de "experiencia" en R. Castillo, "Desde un punto de vista pragmático: Quine y sus críticos".

13 "Existence, Value and Criticism", p. 304. Siempre se suelen citar los famosos y polémicos pasajes de Pragmatismo, pero James se explica mucho mejor en The Meaning of Truth: "si se sigue el método pragmático y se pregunta: ¿Cómo se distingue la verdad? [What is truth known-as?, ¿en relación con qué?] ¿Qué supone su existencia en términos de resultados concretos? [What does its existence stand for in the way of concrete goods?] [...] Su nombre es el inbegriff de casi todo lo que es valioso en nuestras vidas. Lo verdadero es lo opuesto a todo cuanto es inestable, decepcionante en términos prácticos, inútil, engañoso y no fiable, inconsistente y contradictorio, inverificable e injustificable, artificial y extraño, o a todo lo irreal en el sentido de carecer de importancia práctica. Éstas son, con creces, las razones pragmáticas de por qué deberíamos preferir la verdad [turn to truth]: la verdad nos salva de un mundo de esta índole [Truth save us from a world of that complexion]" (The Meaning of Truth, p. 48). En un ensayo publicado veinte años antes que Pragmatismo, "The Sentiment of Rationality", James ya planteó su respuesta: la verdad se reconocerá como se reconoce todo lo demás, por una serie de signos como el equilibrio, la previsión, la armonía, la congruencia, la fiabilidad, la oportunidad, la belleza, el provecho, la utilidad, la riqueza... con toda la vaguedad que arrastran estos criterios. Estos signos pueden, alternativamente, ser de igual importancia para la verdad. Es decir, unas veces uno es más importante y otras veces otro. La verdad, en cualquier caso, no es una propiedad especial de las creencias que se capte de una forma extraordinaria, sino una propiedad empírica que predicamos de ellas cuando 
Dewey siguió a James en este punto y volvió a insistir en que lo verdadero debía entenderse como una especie de bien. En Reconstruction in Philosophy afirmaba: "decir que un hombre busca la salud o la justicia es lo mismo que decir que busca vivir saludable o justamente. Estas cosas, lo mismo que la verdad, pertenecen al adverbio". ${ }^{14} \mathrm{O}$ sea, decir que buscamos la verdad es decir que buscamos formas de conocer que nos guíen verdaderamente. Y un poco antes, después de afirmar que las teorías son instrumentos para reorganizar la experiencia y que la prueba de su validez estriba en la resolución de dificultades concretas, añade:

Si salen con éxito en su función, son fiables, sanas, válidas, buenas, verdaderas. Si cuando se actúa apoyándose en ellas no logran disipar la confusión, ni eliminar fallos, si aumentan la confusión, la incertidumbre, el mal, entonces son falsas. La confirmación, la corroboración, la comprobación radica en su obrar, en las consecuencias. Es bello lo que obra bellamente. Por sus frutos los conoceréis. Lo que nos guía verdaderamente es verdadero; se entiende precisamente por verdad la capacidad probada de ese tipo de orientación. El adverbio "verdaderamente" es más fundamental que el adjetivo "verdadero", y que el sustantivo "verdad". El adverbio expresa un modo, una manera de obrar. Pues bien, una idea o un concepto es una pretensión, un requerimiento o un plan para obrar de cierta manera como medio de llegar a dilucidar una situación concreta. Cuando actuamos sobre la base de ese requerimiento, plan o pretensión, entonces nos guía verdaderamente o falsamente;nos conduce hasta nuestra finalidad o en otra dirección distinta. Lo que tiene máxima importancia en su función operante, dinámica, y toda su verdad y falsedad radica en la calidad de obrar a que nos induce. La hipótesis que funciona en la práctica es la única verdadera; y la verdad es un sustantivo abstracto que se aplica a la serie de casos, reales, previstos y deseados que se ven confirmados en sus obras y en sus consecuencias. ${ }^{15}$

Haack tiene motivos fundados, pues, para sospechar de Dewey, máxime cuando éste llega a sostener que podría ser la filosofía (y, en particular, la propia epistemología) la que separa lo que el sentido común ve como algo unido, la que divorcia la búsqueda de la verdad de la búsqueda general de lo satisfactorio. ${ }^{16}$ En vez de hablar de creencias o hipótesis verdaderas deberíamos hablar, más adecuadamente, de que son correctas o que

las adquirimos por razones concretas y cuando su mantenimiento nos procura resultados concretos (incluyendo resultados cognitivos, claro); generalmente, el resultado concreto más inmediato es la adquisición de otras creencias, o la revisión de las antiguas, etcétera.

${ }^{14}$ Essays, Miscellany and Reconstruction in Philosophy published during 1920, The Middle Works, p. 175. Utilizo, con algún cambio, la traducción de Amando Lázaro Ros, La reconstrucción de la filosofia.

${ }^{15}$ Ibid., p. 69; las cursivas son mías.

${ }^{16}$ Permítaseme citar estas insustituibles palabras de Dewey: "construir una teoría del conocimiento que haga necesario negar la validez de las ideas morales, o bien que obligue a referirlas a algún universo distinto y separado del que habitan el sentido común y la ciencia, es provinciano y arbitrario. El pragmatista al menos ha intentado plantar cara, y no hurtar 
yerran, que satisfacen o no ciertos fines, que responden adecuadamente a una situación o no. La verdad, en efecto, es algo demasiado abstracto y vacío, fácil de invocar pero difícil de precisar. Podemos decir, en efecto, que la hipótesis de que hay vida en otros planetas será verdadera si y sólo si hay vida en otros planetas, pero o nos explicamos más o no decimos nada informativo y relevante. O explicamos en qué condiciones aceptaríamos esa hipótesis, qué criterios de comprobación aplicaríamos... o no decimos más que una tautología, absolutamente verdadera pero vacía. ${ }^{17}$ Rara vez se verá a los propios científicos calificar a una de sus hipótesis o teorías de "verdadera", sino más bien de "mejor", "más satisfactoria", "más adecuada" o "más exitosa" para la solución del problema que tienen entre manos. Como decía Sidney Hook en su libro sobre Dewey: las ideas, como las herramientas, se juzgan normalmente o diariamente en esos términos, aunque la epistemología trate de convertirlas en algo con un naturaleza distinta. Cuando decimos que un diagnóstico médico es "mejor" o "más satisfactorio" que otro, nadie se lleva las manos a la cabeza por usar esos términos (ni considera ese juicio una expresión de una preferencia arbitraria, dado que el paciente, las técnicas médicas y un conjunto de hechos observables operan como controles del diagnóstico). Sin embargo, la epistemología ha tratado de convencernos de que no está bien juzgar en estos mismos términos las ideas. ${ }^{18}$

Para Dewey, igual que para James, la verdad es algo totalmente experimentable, esencialmente conectado con los intereses humanos. Puede incluso decirse que la verdad es correspondencia, en un sentido perfectamente ordinario, llano y común; en el sentido, decía Dewey, en que una solución se corresponde con un problema, o sea, en el sentido en que responde a los requerimientos que plantea una situación. El sentido que un pragmatista puede darle a la idea de correspondencia es ése, una respuesta o ajuste tentativo, "un encaje mutuo entre una situación, las respuestas que provoca y los efectos que tienen éstas". ${ }^{19}$ Si la filosofía ha dado otro contenido supraempírico a la idea de correspondencia es porque de esa forma ha podido justificarse a sí misma, o sea, distinguirse como un tipo especial

el bulto, a la pregunta de cómo es que el 'conocimiento' moral y el científico pueden referirse a uno y el mismo mundo. Y sean cuales fueren las dificultades que plantea la solución por él ofrecida, la idea de que los juicios científicos deben asimilarse a los morales está más cerca del sentido común que la teoría de que hay que negarles validez a los juicios morales porque no cuadran con una teoría preconcebida sobre la naturaleza de ese mundo al que los juicios científicos deben referirse. $\mathrm{Y}$ todos los juicios morales versan sobre cambios que es preciso hacer" ("El carácter práctico de la realidad", pp. 163-164; las cursivas son mías).

${ }^{17}$ Putnam, todo sea dicho, ya advirtió esto en Razón, verdad e historia (Reason, Truth and History), o sea antes de virar definitivamente hacia el pragmatismo.

${ }^{18}$ Sigo en este punto los comentarios de Hook sobre Dewey que se encuentranen el capítulo "Verdad" de su John Dewey: semblanza intelectual, p. 63 y ss. Véase también la introducción de Á. Faerna a La miseria de la epistemología.

19 "Short Catechism Concerning Truth", p. 65. 
de reflexión, un conocimiento diferente y superior al que nos procuran las ciencias:

Podría decirse que los abundantes testimonios de suprema devoción a la verdad que ha manifestado la filosofía es un asunto de lo más sospechoso, pues generalmente ha sido un medio para reclamar una facultad especial de acceso a la verdad suprema y última. Pero no es así, y no perderá su aire esotérico y engañoso hasta que la profesión sea puesta en entredicho. La verdad es una colección de verdades, y esas verdades componentes son asunto de los mejores métodos disponibles de investigación y contrastación, métodos que, cuando se los reúne bajo un solo nombre, bautizamos como ciencia. Respecto de la verdad, pues, la filosofía no goza de una posición preeminente. ${ }^{20}$

Llamamos verdaderas, pues, a todas aquellas creencias que, de momento, consideramos justificadamente buenas, provechosas, ventajosas; pero lo que explica que esas creencias resulten buenas según nuestros mejores métodos disponibles no es que sean verdaderas; lo que lo explica son un montón de hechos y resultados. Si la filosofía no posee una posición preeminente respecto de la verdad, tampoco la tiene sobre la naturaleza del conocimiento. El conocimiento sobre el conocimiento sólo podía ser una explicación histórica, psicológica, sociológica... una reflexión sobre cómo se han llegado a fijar creencias (científicas, morales o políticas).

El conocimiento no es ni más ni menos que aquello que hacemos cuando conocemos [...], una actividad perfectamente cotidiana en sus formas más comunes y que puede alcanzar un alto grado de refinamiento y sofisticación en la modalidad de la ciencia. El conocimiento es un hecho, no un problema. Pero, como todo hecho, necesita descripción, comprensión; como toda actividad, es susceptible de autoconciencia y de perfeccionamiento. Por qué lo que hacemos recibe a veces la denominación honorífica de "conocimiento" [...] es cosa digna de investigarse [...]; tal investigación nos llevaría en la dirección opuesta a los rompecabezas epistemológicos y nos acercaría progresivamente al entramado real de nuestras relaciones con "los hechos". ${ }^{21}$

Sin embargo, la epistemología ha seguido en sus trece. Incluso aquellos pensadores y aquellas pensadoras que están en perfecta disposición de asimilar ciertas lecciones de la ciencia (Dewey ponía en su día el ejemplo de la biología y la idea de evolución) conservan sin cuestionar una teoría del conocimiento que muchas veces es incompatible con los propios hechos

${ }^{20}$ Experience and Nature, p. 307. Quizás la metáfora de una correspondencia entre las ideas y el mundo — dice Rorty — fue inspirada por esa misma necesidad de estar en contacto con una autoridad sobrehumana que llevó a ciertas castas sacerdotales a considerarse superiores a los guerreros. Véase R. Rorty, Philosophy and Social Hope, p. 269.

${ }^{21}$ Á. Faerna, introducción a J. Dewey, La miseria de la epistemología, p. 16. 
que el conocimiento empírico está proporcionando: "la epistemología, al crear la idea de que el modo de formarse concepciones correctas consiste en analizar el conocimiento, ha reforzado este punto de vista. Pues ello conduce inmediatamente a la opinión de que las cosas han de tener ellas mismas una configuración teórica e individual y no práctica", opinión, sigue diciendo, quizás más afín a los idealistas, pero también propia de los realistas que, sobre la base de sus propias teorías del conocimiento, también afirman cómo deberían ser las cosas, en lugar de aceptar la guía de las cosas (tal como nos las describe el conocimiento corriente) para establecer qué es el conocimiento. ${ }^{22}$

Vistos así, James y Dewey podrían ser antecedentes de un pragmatismo eliminacionista cuyo punto de unión, creo yo, quizás serían argumentos tan vagos como que las personas deseamos poseer conocimiento, conocimiento valioso, provechoso, bueno (¿podría ser de otra forma?), que deseamos buen conocimiento por muchas razones, pero que el conocimiento no tiene un fin intrínseco, la verdad, un fin que lo define. ${ }^{23}$ La comprensión (psicológica, sociológica, histórica...) de cómo ciertas creencias llegan a ser aceptadas en distintos contextos, cómo resultan satisfactorias en relación con los problemas que las suscitaron, es suficiente para inspirarnos la confianza de que son mejores que las meras opiniones, pero también para infundirnos la humildad de que no son absolutas. ${ }^{24}$ La explicación de cómo las verdades se abren camino en el mundo de la conducta humana es todo lo que se necesita. Examínense los contextos en los que se aceptan ciertas creencias como justificadas y se rechazan otras como injustificadas y se tendrá todo lo que requiere una explicación pragmatista de la verdad, una explicación tan empírica como cualquier otra y sometida al mismo tipo de control. Las creencias mismas nos van explicando cómo conocemos, y este hallazgo, por falible que sea, posee fuerza normativa, o sea, nos orienta en nuestra búsqueda de conocimiento mejor y más fiable.

22 J. Dewey, "El carácter práctico de la realidad", pp. 159-160.

${ }^{23}$ Rorty ha expresado esto mismo de otras formas, compatibles, creo, con el lenguaje de James y Dewey: conocer y justificar nuestro conocimiento son actividades con muchas metas a la vista, pero no tienen una meta suprema llamada "verdad". Son actividades en las que los seres humanos no podemos dejar de involucrarnos, pero no necesitamos una meta denominada verdad, igual que los estómagos no necesitan una meta llamada "la salud" para funcionar bien. Las metas de los estómagos están en función de los alimentos específicos que procesan, igual que las metas de nuestras creencias vienen establecidas por las distintas situaciones o problemas que afrontamos (véase "La verdad sin correspondencia", p. 35). Sobre la "verdad", quizás sólo se puede decir lo que Dewey dijo justamente sobre la "salud" en su "Theory of Valuation": el médico no tiene una idea de la salud como un fin en sí mismo y absoluto que determina lo que hay que hacer. Por el contrario, el médico construye o forma la idea de salud como un fin a la vista para una situación sobre la base de lo que sus técnicas de análisis han mostrado como problemas del paciente y como posibles soluciones.

${ }^{24}$ S. Hook, John Dewey: semblanza intelectual, p. 70. 
Enfocando a James y Dewey de este modo, pues, podríamos verlos como antecedentes de un empirismo que, a diferencia del positivismo lógico, no concibe la filosofía como una fundamentación del conocimiento y que, por tanto, a ojos de los reformistas, corre el riesgo de subordinarla a las propias ciencias; es decir, de convertirla en un capítulo de la psicología empírica y otras ciencias que estudian el desarrollo del conocimiento humano. Muchos pragmatistas radicales, desde luego, narran la historia del pragmatismo como si James y Dewey condujeran hacia una naturalización de la epistemología, una naturalización que muchos asociarían con Quine.

Es comprensible, pues, que Haack intente contrarrestar esta tendencia radical, aunque no tenga más remedio que aceptarla. En "Viejo y nuevo pragmatismo", ya lo he dicho, Haack considera el cientificismo a ultranza de Churchland y de Stich como una radicalización del naturalismo de Quine. "Churchland — dice Haack- es un entusiasta del estilo más científico, más revolucionario y menos peirceano del naturalismo de Quine" (VNP, p. 49; las cursivas son mías). Así pues, aunque algunas ideas de Quine guarden afinidad con las de Peirce (VNP, pp. 47-48), parece imposible extirpar el germen del radicalismo en Quine. De hecho, Haack acaba diciendo:

[L]a postura de Quine resulta equívoca [... ]; el cuadro peirceano queda confundido, en ocasiones dentro de un cientificismo reformista en el que la epistemología se "asimila a la psicología empírica" [...]; en otras, [queda confundido] dentro de un cientificismo revolucionario que sostiene que las cuestiones epistemológicas son ilegítimas y que deben ser abandonadas a favor de cuestiones psicológicas legítimas. ${ }^{25}$

Como siempre, me temo, Haack sólo parece capaz de juzgar al resto de los pragmatistas según el grado con el que se distancian de Peirce o, más bien, el grado con el que vulneran los principios reformistas según los entiende Haack. Quine no es un caso diferente, dado que separa las teorías filosóficas sobre la naturaleza de la verdad de las teorías sobre la adquisición de creencias. Sobre la verdad —dice él—, poco hay que decir, o mejor: todo lo que se puede decir sobre la verdad no es relevante para la epistemología, ni debería mezclarse con ella. Predicar verdad de una oración es lo mismo que afirmar la oración. Por ejemplo, predicar verdad de "la nieve es blanca" es lo mismo que predicar blancura de la nieve. Por lo que se refiere al concepto de verdad, pues, Quine cree que poco se debe añadir al análisis de Tarski. La gente no debería devanarse los sesos con la naturaleza de la verdad; "verdadero" es un adjetivo transparente. Ahora bien, si llamar verdadera a una oración no es más que afirmarla, ¿en qué nos basamos para afirmarla o no? Buena pregunta, desde luego; pero no una pregunta que sea asunto

${ }^{25}$ VNP, p. 48. También he intentado aclarar este tema en "Desde un punto de vista pragmático: Quine y sus críticos". 
de la filosofía, ni menos aún de las teorías filosóficas de la verdad, sino más bien de una reflexión sobre nuestros métodos de conocimiento. Cómo decidimos si una creencia es verdadera es algo que depende totalmente de la creencia de que se trate... mirar los hechos, hacer experimentos, etc.; pero sea lo que sea lo que nos conduzca a aceptar esa creencia, a integrarla en nuestro cuerpo de creencias, eso también es lo que nos conduce a llamarla verdadera.

Si se hace la pregunta metafísica ¿qué es lo que hace que una teoría sea verdadera y otra falsa?, sólo puedo responder con vano realismo, que la naturaleza del mundo [...]; esta pregunta metafísica ha sido frecuentemente planteada como una cuestión epistemológica, a saber, ¿cómo podemos saber que una teoría es verdadera y otra falsa? Esta pregunta es realmente distinta y más seria que la otra [...]. Si preguntamos por qué tiene más garantías nuestra creencia en una teoría que nuestra creencia en otra, la cuestión que planteamos es sustancial. Una respuesta completa sería una teoría completa sobre la evidencia observacional y el método científico. ${ }^{26}$

La teoría de la verdad y la epistemología, la teoría sobre qué métodos usamos para elegir creencias, quedan, pues, divorciadas hasta un punto que Haack no puede admitir. Con todo, habría que subrayar algunas diferencias entre Quine y otros pragmatistas radicales o propensos al radicalismo. A diferencia de radicales como Rorty, Quine sigue otorgando cierta primacía a la ciencia como patrón de conocimiento, mientras que los radicales como Rorty sólo ven la ciencia como una práctica más, una forma particularmente persuasiva de llegar a acuerdos o, como mucho, un modelo ejemplar de [¿solidaridad humana?] (VNP, p. 50). Sin embargo, el hecho de que Quine se incline a favor de la ciencia no sería suficiente para calmar las preocupaciones de Haack, ya que la forma en la que Quine otorga esa primacía a la ciencia no es suficientemente filosófica. ${ }^{27}$

Pero, dejando a un lado a Quine, el caso intermedio que más me sorprende es el de Putnam. Mientras que en "Pragmatism" Haack reconocía, al menos, sus méritos reformistas como poblador de una tierra intermedia entre el relativismo y el realismo, en "Viejo y nuevo pragmatismo" la referencia a Putnam es demasiado escueta y desconcertante (Putnam —se

${ }^{26}$ W.V.O. Quine, "Respuesta a M.J. Cresswell”, p. 214; las cursivas son mías. Véanse más detalles sobre la posición de Quine también en mi "Desde un punto de vista pragmático".

${ }^{27}$ Realmente Rorty y Putnam creen que también se habría de ir más allá de Quine, aunque por razones distintas e incluso opuestas. Para Rorty, la eliminación de dogmas epistemológicos incluiría la predilección de Quine por la ciencia así como su adhesión a ciertos principios "empiristas". O para decirlo de otro modo: Rorty quiere ser más eliminacionista que Quine, y no sólo disolver conceptos como el de "verdad", sino conceptos como el de "ciencia dura" o "esquema conceptual de primer orden". Putnam también cree que hay que ir más allá de Quine, pero, según él, porque Quine elimina demasiadas cosas y hace incomprensible la racionalidad de la ciencia. Véase también mi "Desde un punto de vista pragmático". 
limita a decir - une los temas abordados por James y Wittgenstein, VNP, p. 48). Quizás Haack no presta tanta atención a Putnam en "Viejo y nuevo pragmatismo" (las referencias a Putnam en Evidencia e investigación y en el Manifesto también son significativamente escasas) porque, para bien o para mal, Putnam está reivindicando el mismo terreno que Haack, un terreno alejado de las adhesiones al realismo metafísico pero también del relativismo o del convencionalismo. Puede ser que el pragmatismo del último Putnam resulte algo oscuro, pero sería injusto desconsiderar su perspectiva y asociar el pragmatismo reformista únicamente con la versión de la propia Haack. Las ideas de Putnam sobre la conexión entre hechos y valores (sobre el papel de los hechos en un mundo de valores, según rezaba el título de un ensayo suyo) o su teoría del realismo común, ha sido uno de los capítulos más importantes de esa nueva ola de pragmatismo que crece desde los ochenta, tan importante como la epistemología del sentido común o el fundaherentism de la propia Haack. Es cierto, desde luego, que Putnam parece tener más elementos radicales que Haack, y que diluye la idea de verdad más de lo que Haack y los reformistas tolerarían, pero mucho menos de lo que Rorty y los radicales están dispuestos.

En efecto, para Putnam, "verdadero" es más que un término de aprobación para las creencias justificadas o justificables. Que la verdad es algo más sustantivo, dice él, es algo que se refleja en el habla común, en la vida corriente, en el sentido común:

Tenemos una noción de verdad, aunque no tengamos una explicación de la "naturaleza de la verdad" [...]; en mi opinión la verdad es una propiedad de las oraciones que decimos y escribimos, una característica que deseamos que tengan las oraciones cuando no tratamos de engañarnos unos a otros, o a nosotros mismos [...]; lo que propongo es aceptar la noción "vulgar" de verdad [...]. No es de la noción de verdad de lo que hay que desembarazarse, sino más bien de un concepción particular de cómo esa noción ha de ser fundamentada [founded] y mejorada [improved] por la filosofía. ${ }^{28}$

Como vemos, todas las sectas pragmatistas parecen reivindicar el punto de vista del sentido común, de la práctica, etc.; pero no parece que lleguen fácilmente a un acuerdo sobre cuál es exactamente la actitud más común hacia el concepto de verdad. Putnam también lee a su manera a James y a Dewey para arrimarlos a su propia epistemología del sentido común, una epistemología que, repito, no es tan eliminacionista como la de Quine y la de Rorty, pero de nuevo insuficiente para una reformista como Haack. ${ }^{29}$ Sea como sea, lo que querría señalar es que el retrato de familia que Haack presenta en "Viejo y nuevo pragmatismo" resulta algo incompleto sin Putnam.

${ }^{28}$ H. Putnam, Words and Life, pp. 264-265.

${ }^{29}$ Véase cómo defiende Putnam un concepto sustantivo de verdad en "Desde un punto de vista pragmático", pp. 268-280. 
No debería ser ella, por tanto, la que reprochara a otros (concretamente a Rorty, VNP, pp. 51-52) el hecho de que borren de la foto de familia del pragmatismo a Peirce o que retoquen a su gusto a James y a Dewey. ${ }^{30}$

Sea como sea, ninguno de los casos intermedios más importantes, diría yo, es asimilable al reformismo, o sea, en todos los casos pesan demasiado sus inclinaciones radicales. Haack, digámoslo así, deja poco espacio, dado que identifica el reformismo con un pragmatismo para el cual los conceptos de investigación, creencia y justificación están intrínsecamente conectados con el de verdad, entendido éste como un objetivo fundamental y específico del conocimiento empírico; es decir, algo que lo hace ser tal y que es independiente de los intereses (incluidos intereses cognitivos como la relevancia). ${ }^{31}$ Algunos pragmatistas del grupo intermedio, sin embargo, ciertamente admiten que los conceptos de verdad, creencias y justificación

${ }^{30}$ Por decir todo lo que se me ocurre: ¿̇por qué Nelson Goodman no se incluye en la historia del pragmatismo? Yo siempre he sostenido que lo que Goodman dice sobre la verdad en Maneras de hacer mundos es de las cosas más pragmatistas que se han escrito nunca (aparte de la alusión a James en la p. 18). Supongo que Haack pondría a Goodman junto a los más radicales, y no en el grupo intermedio, sobre todo cuando dice cosas como éstas: se engaña el científico que se concibe dedicado por entero al único propósito de buscar la verdad, pues en el fondo podría obtener un montón de verdades, aunque triviales, irrelevantes o redundantes, cuando en el fondo "busca sistema, simplicidad, perspectiva y una vez que se siente satisfecho en ese nivel de cuestiones, corta la verdad a medida para que le encaje" (ibid., p. 38). En vez de hablar de la verdad de las teorías, por tanto, "deberíamos decir que son correctas o que yerran [... ] dado que la fuerza lógica, la consistencia y la amplitud, la capacidad de información y el poder organizador de todo el sistema" (ibid., p. 40) ganan en importancia a la verdad cuando hay que elegir entre teorías (ibid., p. 163). Por tanto, no es que la verdad no sea una condición suficiente para elegir entre teorías, sino que en demasiados casos no es necesaria: la mayoría de las leyes y teorías no son diligentes y remilgados informes de datos detallados, sino simplificaciones a lo Procusto (ibid., p. 165) o generalizaciones que no contradicen otras creencias que valoramos. "Hemos de usar algún método para comprobar y juzgar verdades, e ideas como la utilidad o la coherencia se convierten en importantes candidatas para tal papel. Lo máximo que podría demostrar el hecho de que nos sea fácil presentar ejemplos claros de confusas e inútiles verdades y de claras y útiles falsedades es que los mencionados sistemas para comprobar la verdad tienen un carácter más corroborativo que concluyente. No es, en efecto, necesario que una buena comprobación sea concluyente..." (ibid., p. 165), todo lo que se requiere es una correlación razonablemente fiable. "En ausencia de una caracterización definitiva e informativa de lo que pueda ser la verdad, no es dado aplicar varios tests que podemos confrontar y comprobar entre sí y en referencia también a una clasificación anterior, parcial y aproximada, de los enunciados como verdades o falsos" (ibid., p. 166). Véase después (ibid., p. 167) cómo Goodman explica la noción pragmatista de utilidad.

${ }^{31}$ De hecho, Haack separa la verdad como un aspecto independiente del objetivo del conocimiento que no se reduce a un interés del conocimiento, aunque me llevaría demasiado lejos explicar este particular. El fin de la investigación (dijo en "Pragmatismo vulgar: una perspectiva nada edificante", en Evidencia e investigación, p. 272) es obtener la mayor cantidad posible de verdad interesante e importante, pero ese objetivo se divide en la verdad y en la importancia o interés. Desde luego, existen demasiadas verdades que no son ni importantes ni interesantes, y es mucho más fácil obtener verdades si a uno no le importa que sean triviales; pero aun así hay que distinguir el interés de la verdad del puro tratar de averiguar cómo son las cosas. 
están conectados, pero de una forma práctica y poco filosófica; y también creen que dar un contenido sustantivo a la idea de verdad sería como poner el carro delante de los burros. La conexión entre verdad y justificación es un asunto concreto que depende de la clase de creencias y de situación, y no un tema sobre el que la filosofía pueda decir algo muy interesante.

\section{3. ¿Por qué tanta epistemología?}

Paso a otro asunto bastante llamativo. A Haack le interesa el pragmatismo como una contribución a la epistemología entendida como un área más o menos específica de trabajo intelectual, un campo cada vez más interdisciplinario pero no por ello menos definido. En "Viejo y nuevo pragmatismo" alude a algunas ideas de los pragmatistas sobre temas morales y sociales, pero de una forma demasiado distante y sólo como corolarios de posturas epistemológicas. Que James tuviera actitudes un tanto radicales en temas de moral no pinta mucho, aunque Haack alude a ellas (VNP p. 36) solamente para subrayar la propensión de James hacia un peligroso antiintelectualismo. Que Dewey promoviera un socialismo ciertamente reformista pero bastante más radical que muchas otras iniciativas políticas de su época tampoco pinta mucho en la caracterización que Haack hace de él, a saber: un pragmatista a medio camino entre Peirce y James en temas de lógica y epistemología, además de teórico de la educación y de la democracia. ${ }^{32}$ Que Putnam discuta con Nussbaum o con los comunitaristas sobre la relación entre valores universales y comunitarios tampoco importa mucho, y que Rorty escriba cada vez más sobre política y se declare reformista convencido (no importa lo radical que resulte en epistemología) tampoco pinta nada en su esquema o clasificación.

En su cuadro histórico, insisto, lo que cuenta para ser reformista o radical es qué actitud se tiene hacia conceptos fetiche de la epistemología como el de verdad. Haack, digámoslo así, frena en seco en cuanto el pragmatismo se inclina demasiado hacia algo que exceda esos conceptos de la epistemología profesional. Pero, después de todo, si queremos tomar una foto de familia del pragmatismo, ¿qué marca la diferencia para dividir en grupos a los retratados? ¿Los temas de la epistemología, tal como la entendemos hoy, o las inquietudes intelectuales de los retratados?

\footnotetext{
32 Pero, incluso cuando habla de Dewey como teórico social, Haack dice cosas cuando menos improcedentes, como cuando afirma que la insistencia de Dewey en la conexión entre educación y relaciones sociales lo convierte en un alentador de una nociva politización de la educación (véase p. 42), comentarios que, por su generalidad, me parece a mí, deslucen bastante su trabajo; lo mismo ocurre cuando aplica el calificativo de "misticismo romántico" a la teoría de Dewey de la democracia como forma de vida en vez de como forma de gobierno (ibid., p. 41). Quizás Haack está tan preocupada por luchar contra ciertas modas intelectuales que, me temo, confunde a Dewey con el origen del problema en vez de con la solución, pero luego volveré sobre esto.
} 
Es cierto que las obras de James y Dewey se estudian como capítulos de la epistemología; pero ¿no tendría más sentido leer a James a la vez que a John Stuart Mill, el verdadero padre de su pragmatismo?, ¿o a la vez que Kierkegaard, Royce, Adams, Comte, Spencer, Santayana o Bergson? ¿No resulta más provechoso leer a Dewey en compañía de Durkheim, Marx, Mead y Weber, que en compañía de Carnap, Neurath, Russell o Quine? (En realidad, habría formas más históricas de hacer esto último, es decir, formas de leer a pragmatistas y positivistas que no sólo se centraran en los temas fetiche... Neurath tenía opiniones sobre educación y Russell tenía opiniones sobre política que se pueden estudiar a la par que las de Dewey.) $)^{33}$ En realidad, ¿no lee Haack a los pragmatistas clásicos totalmente fuera de contexto, incluyendo, me atrevería decir, a Peirce? Si los leemos en contexto, me temo, reducir el pragmatismo a una contribución a la epistemología es, cuando menos, insuficiente, por no decir otra cosa. ¿No deberíamos agrupar a los pragmatistas según los fines o propósitos que cada pragmatista persigue incluso cuando habla de epistemología?, ¿cuáles fueron o cuáles son los problemas prioritarios para cada pragmatista?

Y ¿qué respecto a los neopragmatistas? ¿Cuáles han sido las preocupaciones más constantes de Rorty, por mucho que haya escrito sobre asuntos de epistemología? ¿Cuáles son, finalmente, sus interlocutores principales? ¿No lo son Habermas o Derrida más que Davidson o Brandom? Si tenemos en cuenta un contexto amplio (llamémoslo historia de las ideas, o historia cultural), si consideramos la amplitud de intereses de cada pragmatista y el horizonte último de sus preocupaciones intelectuales, ¿no deberíamos agrupar más juntos en la foto a James, a Dewey y a Rorty, y dejar definitivamente al otro lado a Peirce, a Quine y quizás a Haack? ¿Deberíamos colocar a Putnam hacia el medio, quizás también con Haack? En cualquier caso, ¿no pesa más que ninguna otra cosa la inclinación hacia temas morales, políticos y sociales? Después de todo, quizás el pragmatismo no sea tan importante como episodio o capítulo de la epistemología, pero sí como capítulo de la crítica social o cultural, una crítica que, desde luego, incluye discusiones sobre el conocimiento científico pero con una óptica distinta de la que adopta la epistemología pospositivista.

Visto desde la óptica de Dewey, la miseria de la epistemología (por decirlo con la acertada expresión de Ángel Faerna) consistiría en eso, en desligar sus reflexiones sobre el conocimiento de un contexto más amplio, un contexto en que el conocimiento científico es comprendido fundamentalmente como una práctica social. Quizás también fue John Dewey el primer pragmatista que se tomó más en serio la conexión entre filosofía y cultu-

33 José Miguel Esteban Cloquell ha explicado recientemente la relación entre el enciclopedismo de Neurath y el proyecto educativo y social de Dewey, un capítulo de la historia del pragmatismo y del positivismo demasiado olvidado por los divulgadores de la filosofía de la ciencia y la técnica. 
ra. El desarrollo cultural, en efecto, suscita conflictos que la filosofía debe afrontar sin subordinarse a las ciencias y sin volverse una mera sirvienta de la política, pero tampoco alejándose de la vida práctica y los problemas concretos, atendiendo a preguntas como ¿qué relación hay entre organización social y las ideas sobre la naturaleza del conocimiento?, ¿qué relación existe entre el desarrollo del conocimiento científico y la democracia?, ¿qué lugar ocupa la religión en una sociedad industrial? ${ }^{34}$

Desde luego, Haack diría que si ella da primacía a la epistemología no es porque no le interese la dimensión social del conocimiento, o las consecuencias sociales de una epistemología de talante pragmatista. Para Haack, la epistemología también es una forma de enfocar ciertos temas de mayor calado, problemas que en una formulación menos profesional y filosófica están presentes o laten en el conjunto de las prácticas sociales. La epistemología, desde luego, tiene cosas que decir sobre la verdad, la autoridad de la ciencia o el conocimiento empírico que no sólo interesan a los profesionales de la epistemología — diría sin duda Haack. Y, sin embargo, lo que una epistemología reformista dice sobre esos asuntos lo dice con una actitud distante, con una mirada que no es la de Dios, pero sí la de un espectador que observa una batalla de lejos. La propia Haack, después de todo, defiende su propia versión de epistemología interdisciplinaria; también ella ha ido más allá de la lógica profesional hacia una epistemología de más amplias miras, hasta llegar a sus trabajos sobre feminismo, multiculturalidad y derecho en Manifesto of a Passionate Moderate (actualmente enseña en la facultad de derecho de Miami y está escribiendo sobre la relación entre testimonio y verdad). Si ella se siente obligada a luchar contra el radicalismo pragmatista en la arena de la epistemología, es porque, lo diga o no, cree que tener ciertas visiones de la verdad o de la ciencia es algo que no está desconectado de ciertas nociones del bien o de la justicia. Que Rorty vaya predicando la disolución de problemas filosóficos tradicionales, diría Haack, no es algo que sólo posea consecuencias académicas o profesionales. De hecho, Haack actúa con una actitud parecida a la de Sokal y muchos otros defensores de una epistemología del sentido común, una epistemología que lucha contra ciertas modas intelectuales nocivas socialmente, modas a las que, según ella, han contribuido ciertas formas de neopragmatismo. ${ }^{35}$

\footnotetext{
${ }^{34}$ Véase J.C. Geneyro, La democracia inquieta, E. Durkheim y John Dewey (no convendría tampoco olvidar las conferencias de Durkheim sobre el pragmatismo de James); Á. Faerna, introducción a La miseria de la epistemología; J.M. Esteban Cloquell, La crítica pragmatista de la cultura.

${ }^{35}$ Leo este comentario de Sokal: "Haack labra un camino intermedio entre el viejo conservadurismo (Old Deferentialists) y los nuevos cínicos, y defiende con ejemplar claridad la idea de que la ciencia, aunque no posee un privilegio epistemológico, es una ejemplificación extraordinariamente exitosa del conocimiento racional: la ciencia no es 'ni algo sagrado ni una estafa'. Haack entiende que la ciencia es una empresa social, pero niega que el conocimiento
} 
La foto de la familia pragmatista que toma Haack, pues, está demasiado influida por esta actitud hacia una clima intelectual muy concreto, el de las humanidades en Estados Unidos, un clima creciente de desconfianza hacia el conocimiento científico y la filosofía de aire científico. Es comprensible, por tanto, que Haack subraye la contribución del pragmatismo a una epistemología reformista con ciertos usos sociales, y que critique la propensión del neopragmatismo a mezclarse en el confuso ambiente de una filosofía más literaria y cultural que alienta el relativismo o la idea de que el conocimiento verdadero sólo es una ficción. Lo malo es que Haack no parece hacer distinciones: o uno está con el pragmatismo reformista o se encamina inevitablemente hacia la retórica, las actitudes anticientíficas, el relativismo, el "todo vale" y otras modas asociadas al dichoso posmodernismo...

No me queda claro, sin embargo, por qué Haack encuentra tan peligroso socialmente el neopragmatismo radical, el neopragmatismo disolvente en temas de epistemología. En el caso de Rorty, al menos, lo que parece molestar más a Haack no es que Rorty considere beneficiosa socialmente la eliminación de teorías filosóficas sobre la verdad (por indirectos que sean los beneficios), sino, más aún, que esa política de eliminación sólo sea una forma de practicar la ironía dentro de la epistemología, o sea, una forma de criticar cierta obcecación profesional. Rorty ha sido bastante explícito a este respecto: "Si recojo lo que algunos filósofos han dicho sobre la verdad, es con la esperanza de desalentar a que se siga prestando atención a este tema más bien estéril." 36 Los pragmatistas, dice también Rorty, no tienen argumentos fuertes contra las intuiciones a las que apela Haack (que la verdad es algo sobre lo que puede haber teorías, que es un objetivo que define a un conocimiento bueno), sino sólo argumentos retóricos como ¿qué diferencia suponen en la práctica todas esas posiciones? Este tipo de argumentos - dice Rorty- son el único tipo de preguntas con las que la filosofía puede contribuir a la comprensión de los cambios y conflictos socioculturales. ${ }^{37}$ Por otro lado, un pragmatista radical como Rorty no espera mucho ni de su propio pragmatismo. La conexión entre el pragmatismo eliminacionista y la política democrática es laxa. Su único argumento para abandonar ciertas nociones de verdad es que, de algún modo, perpetúan una imagen de la relación entre personas y lo que no son personas que se podría calificar, dice él, de autoritaria; una imagen en la que las personas están sujetas a algo

científico sea una mera construcción social, y analiza las condiciones sociales y políticas en las cuales los científicos más o menos logran descubrir verdades (o verdades aproximadas) sobre el mundo." Comentario de Sokal incluido en la colección de reseñas que preludia, a modo de publicidad, el Manifesto de Haack.

${ }^{36}$ Verdad y progreso, p. 23. Véase cómo A. de Torre alude a estos argumentos de Rorty en "El efecto Rorty".

${ }^{37}$ Verdad y progreso, p. 61. 
que está por encima de ellas. ${ }^{38}$ (Para decirlo de una forma más provocativa: la epistemología puede concebir la búsqueda de la verdad como la mayor virtud humana, pero para Rorty esa virtud sólo es un sustituto del antiguo temor de Dios.) El antiautoritarismo en epistemología, por tanto, consiste en la eliminación de la idea de verdad u objetividad entendidas como una conexión entre algo humano y algo no humano, igual, dice Rorty, que el antiautoritarismo en ética consiste en desplazar la idea de que lo bueno es algo que reconocemos fuera de nosotros y no un resultado de un legado cultural revisable. ${ }^{39}$

Lo cierto es que Rorty tiene poco de radical, dado que no espera grandes cosas de sus propios ataques a la epistemología: un cambio de imagen, de actitudes, de temperamentos (si se quiere decir con la jerga jamesiana). La epistemología que trata de fundamentar las prácticas sociales no tiene gran utilidad social, dice Rorty, pero tampoco se puede esperar mucho de la propia crítica pragmatista a la epistemología, cuya utilidad sólo es secundaria y relativa. La influencia social de una imagen antiautoritaria del conocimiento y de la ética sólo tiene lugar a largo plazo, como parte de una reforma de las mentalidades, un cambio de actitudes acordes con el espíritu de la democracia occidental.

A mi juicio, esta laxitud intelectual es lo que verdaderamente molesta a Haack de Rorty, más incluso que el eliminacionismo, o sea, el radicalismo en temas de verdad o de objetividad. Para Haack, el papel de la epistemología (sea reformista o radical) no puede ser tan vago como para Rorty; tiene que ser algo más sustantivo, más constructivo: la epistemología tiene que servir para algo más que deshacer o reforzar imágenes, formas o estilos de vida.

\section{4. ¿Qué marca la diferencia en la historia del pragmatismo?}

Es comprensible, he dicho, que Haack tome una foto sin ninguna intención historicista, pero no deja de ser inadecuado. Rorty, me temo, lo ha dicho muy bien. Peirce siempre

se consideró miembro de una comunidad internacional de investigadores que trabajan sobre temas especializados que poco tenían que ver con los desarrollos históricos o con las culturas nacionales. Cuando Peirce hacía referencia a temas políticos y a tendencias sociales, lo hacía con la misma actitud distanciada que adopta Quine, es decir, como algo que tiene poco que ver con la filosofía. ${ }^{40}$

James y Dewey, por el contrario, conectaron su filosofía con problemas morales, sociales y políticos que tenían que ver con la historia cultural de

${ }^{38}$ R. Rorty, Verdad y progreso, p. 179.

${ }^{39}$ R. Rorty, Pragmatismo, una versión, p. 38.

${ }^{40}$ R. Rorty, "Norteamericanismo y pragmatismo", p. 5; las cursivas son mías. 
Estados Unidos y, en conjunto, con la historia de la civilización postilustrada. ${ }^{41}$ Visto así, el neopragmatismo se podría dividir en dos grupos:

(1) Quienes se dedican a temas de epistemología concibiéndose miembros de una comunidad internacional de investigadores, y que, como dice Rorty, "no encaminan en exceso sus preocupaciones hacia la filosofía moral y política ni se ven a sí mismos representando nada que sea peculiarmente estadounidense [...]; sólo Putnam en sus últimos escritos ha dado pasos más allá". ${ }^{42}$ Dentro de este grupo, por tanto, caerían los que Haack separa en su foto (reformistas, radicales o intermedios): Lewis, Quine, quizás el Putnam de los años setenta, Churchland, Stich, ¿Haack misma?

(2) Por otro lado, tendríamos a aquellos que, como el último Putnam, proceden del mundo de la epistemología, pero se encaminan cada vez más hacia esos temas morales y políticos, gente que conecta cada vez más los debates tradicionalmente asociados a la epistemología con problemas sociales (¿habría que añadir también aquí a Haack?); también a aquellos que, como Rorty, quizás sólo han sido epistemólogos circunstanciales más que profesionales y que, al menos en su caso, se han encaminado de forma un tanto apresurada hacia temas éticos, políticos y culturales, dejándose caer por un pendiente demasiado inclinada, una pendiente que no lleva hacia la filosofía moral o hacia la teoría política sistemática, sino hacia un tipo de crítica social sin grandes alardes ni intereses teóricos, una crítica comprometida y edificante, participativa e instructiva, irónica y persuasiva. Finalmente, también podríamos agrupar aquí a aquellos pragmatistas que siempre han estado más encaminados hacia temas morales y políticos, hacia algún género de teoría social de tinte pragmatista; individuos que, como en su día hizo Dewey, se conciben como miembros de una comunidad de científicos sociales comprometidos, o de una comunidad internacional unida por algunos intereses y propósitos comunes, pero no de una comunidad ideal de investigadores desinteresados. Richard Bernstein podría ser un caso (Haack lo coloca a medio camino entre el reformismo y el radicalismo), ${ }^{43}$ pero podrían incluirse personajes que ella no cita, como el inclasificable Cornel West, a medio camino entre el teórico social y el activista.

${ }^{41}$ Dewey manifiesta expresamente el paralelo entre el pragmatismo y el pensamiento ilustrado que quería enfocar los asuntos humanos de un modo experimental y le interesaba la crítica y reconstrucción de las creencias y las instituciones (véase "La evolución del pragmatismo norteamericano" (1925) en Á. Faerna, La miseria de la epistemología, p. 79).

${ }^{42}$ Ibid., pp. 5-6.

${ }^{43}$ Véase la propia versión de Bernstein sobre la historia del pragmatismo en "American Pragmatism: The Conflict of Narratives" (con respuesta de Rorty, donde éste dice que en la historia de Bernstein el centro es Dewey, pero en la suya sería James). 
Es razonable, desde luego, que detrás del grupo (1) sobrevuele el fantasma de Peirce, dado que Peirce actuó con esa actitud distante a la que se refiere Rorty, y no vivió ni se interesó por los conflictos de su tiempo como James y Dewey. Hay, desde luego, formas de leer a Peirce gracias a las cuales su obra adquiere una dimensión que excede la de la epistemología o la lógica. Putnam, creo yo, intentó hacer algo así en Las mil caras del realismo, cuando discutió la idea de racionalidad instrumental y acabó señalando sus afinidades y diferencias con Apel y Habermas, dos europeos, por cierto, que también supieron sacar jugo filosófico a Peirce. Haack misma, no hace falta decirlo, también pretende extraer de Peirce mucho más que lecciones de epistemología... pero, pese a todo, Peirce no pasará a la historia por lo que dijo sobre moral, estética, religión y política, por muy interesante que sea lo que dijo sobre esos temas.

También es razonable que por encima del grupo (2) siempre sobrevuelen los espíritus de James y Dewey. James siempre estuvo volcado hacia temas de moral y religión (aunque muchos creemos que dijo cosas muy sensatas sobre ciencia) y su estilo fue, sin duda, el menos científico o distante y el más literario, pictórico, retórico... ¿cómo habría que describirlo? El público al que James se dirigía, desde luego, no era el de una comunidad ideal de investigadores desinteresados.

Peirce — decía ya Dewey— era por encima de todo un lógico; pero James era un educador y humanista que quería forzar al público general a darse cuenta de que determinados problemas, determinados debates filosóficos, tienen una importancia real para la humanidad, pues las creencias que se ponen en juego conducen a formas de conducta muy diferentes. ${ }^{44}$

Dewey, por su parte, siempre escribió con las miras puestas en la educación, la política, el arte, la religión, aunque dijo cosas más que interesantes sobre ciencias naturales y técnica, cosas que cada día resultan más sensatas a los que se han ido aburriendo de los temas de la epistemología profesional. Su estilo al discutir temas epistemológicos fue más constructivo y sistemático que el de James, y quizás por eso sigue inspirando a gente como Putnam, aunque Rorty siempre ha defendido que Dewey es el pragmatista con más imaginación histórica.

Desde luego, el público al que se quería dirigir Dewey ya no era, como en el caso de James, un público de individuos que se debatían a solas, y que buscaban la forma de dar sentido a su existencia. Dewey no negó la realidad de esos problemas, y también subrayó la conexión entre pragmatismo e individualismo, pero recondujo el pragmatismo hacia lo colectivo, hacia

${ }^{44}$ J. Dewey, "La evolución del pragmatismo norteamericano”, en Á. Faerna, La miseria de la epistemología, p. 67. 
lo social: ¿cómo es posible compartir valores, actuar juntos, crear una sociedad de individuos activos y responsables? Su público fueron educadores, científicos sociales, políticos, sindicalistas, gente involucrada en proyectos sociales, instituciones y grupos sociales, más que investigadores desinteresados. James fue el modelo del intelectual carismático y comprometido, individualista; Dewey el de un crítico social preocupado por la formación de una verdadera opinión pública en su país. ${ }^{45} \mathrm{El}$ problema que afrontó Dewey no era solamente ¿cómo da cada individuo sentido a su vida?, sino ¿cómo podemos organizar una forma de vida común, una cultura?; ¿qué papel puede tener la ciencia y la técnica en esa cultura?; ¿cómo se compagina la tecnología con el arte?; ¿qué pasa con la religión en una democracia industrial ${ }^{46}$ Puede ser que James y Dewey ocupen un lugar secundario en la historia de la epistemología (comparados con Peirce o Quine); pero, desde luego, siempre ocuparán un lugar prominente en la historia de la cultura, al lado de otros moralistas y pensadores sociales. ${ }^{47}$

A donde quiero ir a parar con toda esta digresión es a que Rorty tiene razón: lo que verdaderamente separa en grupos a los pragmatistas es el papel que le otorgan a la filosofía en relación con los conflictos culturales e históricos. Visto así, ni lo esencial, ni lo más útil, ni lo más interesante del pragmatismo tendría que ver con la epistemología, sino con la crítica social. El verdadero horizonte de James y Dewey era la filosofía como una voz social; una voz, ciertamente, que la filosofía estadounidense perdió hace tiempo, pongamos desde la posguerra, cuando el estilo intelectual de Dewey fue desplazado por el de los positivistas, más científico y distante de los asuntos políticos. ${ }^{48}$ Hasta ese momento, el pragmatismo concibió

\footnotetext{
45 Sobre esto, véase el insustituible trabajo de Dorothy Ross, The Origins of American Social Science.

${ }^{46}$ Haack insinúa algo de esto, pero de una forma demasiado apresurada. Por ejemplo, después de decir algunas generalidades sobre el espíritu individualista de James, dice: "los viejos neopragmatistas no eran tan unidimensionalmente comunitarios como parecen serlo algunos neopragmatistas contemporáneos". Exactamente ¿a qué neopragmatistas se refiere?

${ }^{47}$ Por mucho que la epistemología profesional haga un hueco a James, siempre lo considera superficialmente. Dewey es otra historia y quizás, conforme pasa el tiempo, la epistemología se lo va tomando cada vez más en serio.

${ }^{48}$ Rorty narró hace mucho el eclipse de la filosofía pragmatista en "La profesionalización de la filosofía y la cultura trascendentalista" (Consecuencias del pragmatismo). "El de entreguerras fue un periodo de profecía y liderazgo moral, la época heroica del pragmatismo de Dewey, durante la cual la filosofía desempeñó un papel en la vida del país [...]. A partir de la Segunda Guerra Mundial, la filosofía se ha profesionalizado y los filósofos han abdicado deliberadamente de ese papel. En el periodo anterior a la Primera Guerra Mundial [... .], la filosofía se definía por su relación con la religión. En tiempos de Dewey, por su relación con las ciencias sociales. A comienzos del periodo de profesionalización, los filósofos intentaron [...] definir su actividad tomando como referencia las matemáticas y las ciencia naturales [...]; dicho periodo ha estado marcado por su reclusión frente al resto de la academia y de la cultura, por la insistencia en la autonomía de la filosofía" (pp. 127-128; las cursivas son mías). Por supuesto, este grupo pensó que su forma de concebir el trabajo intelectual (un
} 
la epistemología dentro del contexto de la crítica social. En ese sentido, Peirce es menos pragmatista que James y Dewey, por mucho que fuera el padre fundador o el inventor de ciertas reglas o máximas. Para decirlo como Rorty, o sea, de la forma más provocativa posible:

si Peirce no hubiera existido, el curso de la historia de la filosofía no habría cambiado mucho, pues Frege y Russell hicieron bastante en la dirección de la lógica [...]. Peirce es relativamente insignificante, porque, a diferencia de James y Dewey, no se ocupó, como sí hicieron James y Dewey, del problema que dominó la filosofía de Kant y que late en el corazón del pensamiento decimonónico de todos los países occidentales: el problema de cómo reconciliar ciencia y religión, de cómo ser fiel al espíritu de Darwin y al espíritu de Cristo al mismo tiempo. Este problema constituye el paradigma del tipo de conflicto entre viejos modos de hablar y nuevos desarrollos culturales cuya resolución Dewey veía como tarea principal de la filosofía. ${ }^{49}$

Conflictos entre viejas y nuevas formas de ver el mundo, viejos y nuevos vocabularios, como dice Rorty, conflictos cuya comprensión, parece ser, requeriría el tipo de pensamiento imaginativo y reflexivo que el pragmatismo asociaría con la crítica social y cultural. Por eso, aunque Haack hace referencia al horizonte de preocupaciones sociales y políticas del viejo y del nuevo pragmatismo, no profundiza, me parece a mí, en la verdadera dimensión del problema: qué actitud adopta cada pragmatista hacia esos conflictos entre viejos y nuevos modos de pensamiento, si una actitud "científica" o una actitud, no necesariamente anticientífica, pero mucho menos formal y sistemática. Incluso si lo esencial del pragmatismo fuera su insistencia en los problemas prácticos, incluso si su propósito fuera hacerse cargo de los problemas de la gente (como decía Dewey), a los ojos de Haack seguirían persistiendo los dos mismos tipos de actitudes: reformistas y radicales. Incluso si las discusiones de la epistemología pasaran a un segundo plano y se diera primacía a la comprensión y resolución de problemas sociales, una cosa - diría ella — es hacer ciencia social constructiva o reconstructiva, y otra muy distinta practicar un vago ensayismo literario con fines sociales; una cosa es tratar de reconstruir o justificar prácticas sociales, y otra practicar un género vago de retórica. Una cosa son las teorías de Mead y Dewey, por ejemplo, y otra los ensayos de James y Rorty.

La piedra de toque de la clasificación de Haack, pues, sería el grado con que los pragmatistas se dejan llevar por el radicalismo, se trate de

trabajo técnico, analítico y científico, distinto tanto de la filosofía literaria como de la filosofía politizada) también contribuía o estaba al servicio de la democracia. Véase el ensayo entero de Rorty.

${ }^{49}$ El Pragmatismo, una versión, p. 29; las cursivas son mías. Véase cómo Rorty describe la solución de Peirce para el choque entre ciencia y religión en la p. 30 y ss. Véase también, sobre la actitud de Peirce hacia la religión, J. Esteban Cloquell, La crítica pragmatista de la cultura. 
cuestiones epistemológicas o morales. Por eso, cuando describe la decadencia del pragmatismo, dice que el neopragmatismo radical "adopta dos estilos aparentemente contradictorios": (1) "un cientificismo a ultranza" que diluye las cuestiones filosóficas en las ciencias y que ella asocia no sólo con Churchland y Stich, sino también con el propio Rorty, y (2) un "etéreo diletantismo literario" que ella considera como una exacerbación del estilo de James. Estos dos estilos, en efecto, podrían parecer contradictorios, dado que uno disuelve la filosofía en las ciencias, mientras que el otro la diluye en la literatura. Pero, en realidad, dice Haack, los dos practican un mismo y furioso estilo antifilosófico y antiintelectual (VNP, pp. 22-23), o sea, los dos "repudian los proyectos filosóficos tradicionales" (ibid.). En el caso de Rorty, desde luego, estos dos estilos son compatibles dado que los dos sirven para socavar las aspiraciones de la filosofía, pero yo diría que pesa más el lado cultural: Rorty empuja al pragmatismo hacia un estilo intelectual propio de la cultura humanista o literaria y lo aleja de la cultura científica (incluyendo la epistemología moderna), por eso incluso cuando habla de ciencia, su estilo radical y sus fines no tienen nada que ver, creo yo, con el radicalismo de un Churchland o de un Stich, dado que también desea socavar las aspiraciones del propio cientificismo a ultranza, incluso si ese cientificismo sirve, circunstancialmente, para socavar cuestiones filosóficas tradicionales.

Pero vuelvo al punto principal: la cuestión no es solamente que haya un pragmatismo distante de los temas sociales y otro pragmatismo volcado hacia ellos, sino uno que se aproxima a esos temas a través de jergas, planteamientos de problemas y formas de argumentar con un aire científico, y otro que trata de verlos apenas sin grandes teorías ni vocabularios especializados; uno que conserva algunas aspiraciones "científicas" de la filosofía (en temas científicos o sociales) y otro que la transforma o que incluso la diluye en otros géneros de discurso social. La división relevante que articularía la historia del pragmatismo sería entre quienes dan a la filosofía un papel específico (no la fundamentación, desde luego, pero si la justificación o la reconstrucción de las prácticas sociales) y quienes meramente le dan un papel de disolución. Según esta división, Haack estaría a medio camino entre la justificación y la reconstrucción, Dewey y Putnam entre la reconstrucción y la disolución, y James y Rorty más hacia la disolución.

Así pues, las clasificaciones de Haack y las de Rorty curiosamente coincidirían en lo fundamental, aunque sus propósitos fueran los contrarios: lo que marca la diferencia es el peso de la reconstrucción o de la disolución, y no una mera división entre pragmatistas dedicados a la epistemología y pragmatistas dedicados a temas morales. Haack se hace perfectamente cargo de esto cuando comenta que en "Los moralistas y la vida moral" James ya sugirió que las discusiones filosóficas en torno a temas morales se alían con los sermones, los libros sobre política y filantropía y las novelas 
y dramas más profundos... “anticipación muy modesta de lo que llegaría a ser, en una de las ramas del neopragmatismo contemporáneo, un intento revolucionario por disociar el pragmatismo de la ciencia y asimilarlo a la literatura" (VNP, p. 36). Puestos a decir algo como esto, Haack podría afirmar, más exactamente, que el nuevo pragmatismo no es que se vuelque en la literatura y olvide la ciencia, sino que diluye las aspiraciones de la filosofía tanto en el campo de la epistemología como en el de la filosofía moral y política (donde Haack dice "ciencia", en realidad creo que podría decir simplemente "filosofía", filosofía que no se reduce a sermones y cuentos persuasivos, que no es mera conversación).

Y, ciertamente, Haack tiene razones para pensar que Rorty hereda esa actitud de James. Como dijo en La filosofía y el espejo de la naturaleza, participar en una conversación no es lo mismo que colaborar en una investigación. Desde un punto de vista cultural (punto de vista que Rorty oponía explícitamente al epistemológico), cosas como charlar, discutir y convencerse son más importantes que descubrir y poseer verdades, y requieren no descripciones exactas de la realidad, sino un género más creativo e imaginativo de discurso. Los filósofos edificantes no quieren conducir a la filosofía por el seguro camino de la ciencia, ni aspirar a representaciones de algo (el mundo en sí mismo, la naturaleza de las cosas), sino modificar las formas de tomarse las cosas, algo parecido, dice Rorty, a lo que logran los escritores y las escritoras. ${ }^{50}$ Por supuesto, este tipo de tendencia pragmatista es el que más desespera a Haack.

Que Haack asocie a James y a Rorty con un diletantismo literario sobre temas sociales era de esperarse. Más sorprendente, creo, es que nos advierta sobre ciertas tendencias radicales de Dewey. Después de elogiarlo como un reformador de la epistemología, dice:

[H]ay un tema más radical, desarrollado agudamente en un ensayo de 1919, "Philosophy and Democracy", que Dewey abre con una excelente interrogante: "iPor qué filosofía y democracia, en vez de química y oligarquía, matemáticas y aristocracia, astronomía y monarquía?” Responde que la filosofía se concibe mejor, no como una rama de la ciencia, sino como el amor por la sabiduría: "un deseo intelectualizado, una aspiración sujeta a discriminaciones y pruebas racionales, un programa social [...] disciplinado por un pensamiento y un conocimiento serios [...]. La filosofía, así concebida, implica el ejercicio de la imaginación moral, "una sensibilidad hacia el estilo de vida mejor que pueda ser llevado". (VNP, p. 40; las cursivas son mías)

Supongo que lo único que a Haack le puede parecer radical en un pasaje como éste es que la filosofía deje de concebirse como una rama de la ciencia y se convierta en algo tan vago como un arte de vivir o un programa social.

${ }^{50}$ La filosofía y el espejo de la naturaleza, pp. 325, 335. 
Supongo que, para Haack, esto suena radical porque se empieza diciendo este tipo de cosas y se puede acabar diciendo que la filosofía es cuestión de retórica, de sermones o de cuentos. Igual que Dewey, los neopragmatistas rortyanos no conciben la filosofía como una rama de la ciencia; pero, a diferencia de Dewey, ya no esperan grandes cosas de la filosofía, no creen que tenga tanta influencia sobre la política, o que se pueda traducir en un programa social.

¿Cómo podríamos describir el radicalismo en temas de moral y política? Por decirlo en términos parecidos a los que Haack usa para describir el radicalismo epistemológico, se me ocurre la siguiente formulación:

El pragmatismo reformista aún reconoce la legitimidad de una reflexión filosófica sobre el bien y la justicia. El pragmatismo radical no reconoce la legitimidad de cuestiones que trasciendan los modos de hablar y de argumentar corrientes, propios de las prácticas sociales habituales. Para el/la reformista, el bien, la justicia o la racionalidad es algo lo suficientemente sustantivo como para que haya teorías sobre ello. Para el/la radical, ésas no son la clase de cosas sobre las que puedan existir teorías filosóficas interesantes, o sea, no hay nada filosófico que decir sobre los criterios de una acción racional o sobre qué cuenta como acción buena que añada algo a nuestras formas corrientes de distinguir lo bueno de lo malo.

En Contingencia, ironía y solidaridad, Rorty ya defendió la idea de que este radicalismo tuvo a Dewey como precursor. Dewey — decía- ayudó a socavar la idea de que las democracias liberales necesitan fundamentos filosóficos o universales que transciendan la historia. Cuando Dewey socavaba esos fundamentos, su tarea de destrucción era una forma de fortalecer las instituciones democráticas:

Las instituciones liberales se hallarían en situación óptima si se las liberara de la necesidad de defenderse en términos de tales fundamentos [...]; el único modo de justificación que vamos a lograr es el de una justificación circular de nuestras prácticas, una justificación que haga que un rasgo de nuestra cultura parezca bueno remitiéndose a otro, o comparando polémicamente nuestra cultura con otras por referencia a nuestras propias prácticas [...], un triunfo de la Ilustración en el cual ésta se cancela a sí misma y llega a su pleno cumplimiento. El pragmatismo es la antítesis del racionalismo de la Ilustración, aunque sólo fue posible (de forma perfectamente dialéctica) en virtud de ese racionalismo. Puede servir como el léxico de un maduro liberalismo ilustrado (despojado de ciencia y filosofía). ${ }^{51}$

Con todo, este antifundamentalismo de Rorty no convierte necesariamente a la filosofía en puro juego. Haack tiene razón en un punto: Rorty simpati-

${ }^{51}$ Contingencia, ironía y solidaridad, p. 76; las cursivas son mías. 
za con sectores de la crítica literaria antifilosóficos y antiintelectuales. ${ }^{52}$ Sin embargo, Rorty congenia con ellos exactamente por lo contrario de lo que cree Haack. Ella dice que cuando Rorty defiende la primacía de la política cultural sobre la epistemología, la conexión entre su propia filosofía edificante y la política democrática se establece "centrándose -de acuerdo con la moda actual en los estudios literarios- en los aspectos políticos de la literatura" (VNP, p. 51, las cursivas son mías). Sí y no. Sí, porque Rorty establece alguna conexión entre crítica cultural y política; pero no, porque esa conexión, como he dicho antes, es demasiado laxa:

Espero que nosotros, los profesores de filosofía, consigamos evitar tres tentaciones. La tendencia a ver la filosofía como un agente de cambio, y no de reconciliación; la tendencia escolástica a encerrarse dentro de los límites de cada disciplina; y, tercero, la tendencia hacia el chovinismo. Me parece que podríamos evitar todo esto si adoptamos la noción de Dewey de nuestro trabajo como un trabajo de reconciliación de lo viejo con lo nuevo, y de nuestra función profesional como honestos negociadores [brokers] entre generaciones, entre áreas de actividad cultural o entre tradiciones. ${ }^{53}$

Esto, después de todo, no suena nada radical, sino en verdad bastante reformista (en el sentido más ordinario de "radical y "reformista"). Éste es el único estilo de política cultural que Rorty alienta, un estilo moderado y sin grandes aspiraciones teóricas o políticas, un estilo alejado del radicalismo de todos esos grupos posmodernos que intentan extraer de la filosofía y de la teoría literaria bases para una política radical y que confunden la subversión de las ideas con la transformación de realidades.

Por supuesto, no todos los neopragmatistas aceptan esta concepción de la filosofía como mera conversación sin grandes pretensiones teóricas y políticas. Putnam, desde luego, cree que una filosofía pragmatista inspirada en Dewey puede y debe ofrecer algo más: no argumentos tan sustantivos como los de Habermas y Apel, pero tampoco mera retórica, como Rorty. Para Putnam, la filosofía aún proporciona ideas provechosas sobre la relación entre universalidad y particularidad, ${ }^{54}$ mientras que, para Rorty, la filosofía debería prescindir por completo de esa discusión y concentrarse en los detalles, o sea, en las experiencias concretas de personas de distintos

\footnotetext{
${ }^{52}$ Haack alude a Stanley Fish (p. 53), pero debería haber citado a Harold Bloom, cuyas actitudes antiteóricas y antifilosóficas han influido en Rorty mucho más de lo que se cree. Véase, de Fish, "Truth and Toilets: Pragmatism and the Practices of Life". Véanse la alusiones de Bloom a Rorty en Agon. Towards a Theory of Revisionism (p. 19) y las profusas referencias de Rorty a Bloom en Contingencia, ironía y solidaridad y en el último capítulo de Forjar nuestro país.

${ }^{53}$ Véase "Philosophy and the Future", en Rorty and Pragmatism.

${ }^{54}$ Véanse los escritos de Putnam sobre Dewey y la democracia en La herencia del pragmatismo.
} 
lugares que han logrado convivir juntas, experiencias que se transmiten a través de novelas, más que a través de argumentos filosóficos. ${ }^{55}$

Putnam, en definitiva, no rompe totalmente los lazos entre una filosofía apoyada en la epistemología pospositivista y una reflexión filosófica sobre la justificación de la democracia, y, por tanto, sigue siendo el personaje a medio camino entre el reformismo y el radicalismo que más sombra puede hacerle a Haack.

\section{Acusaciones}

Hay otra afirmación de Haack que me deja un tanto perplejo: que los neopragmatismos radicales "se encuentra[n] más cercano[s] al estilo furiosamente antifilosófico del positivismo que al pragmatismo clásico" (VNP, pp. 22-23, las cursivas son mías). Si "pragmatismo clásico" se identifica únicamente con Peirce, tal vez Haack tenga algo de razón: Peirce tenía una concepción de la filosofía como algo más sustantivo que un simple método para determinar el significado de los conceptos y, desde luego, toleró mucha más metafísica que los positivistas. Pero si "pragmatismo clásico" incluye a James y a Dewey, las cosas son más complicadas, dado que James y Dewey fueron, en efecto, más antifilosóficos y antiintelectuales que Peirce, pero en un sentido que los empujó a calificar de intelectualistas a los propios positivistas de su época. Para James y Dewey, el "intelectualismo" era un prejuicio filosófico que padecían tanto los metafísicos como ciertos empiristas y positivistas.

Que yo sepa, los cruces de acusaciones entre pragmatistas y positivistas siempre discurrieron en esos términos: los pragmatistas tacharon a los positivistas de intelectualistas; es decir, de no dejarse guiar por la práctica y los descubrimientos de las ciencias, de proyectar sobre la realidad ideas preconcebidas acerca de la naturaleza del conocimiento. Los positivistas, en cambio, acusaron a los pragmatistas de antiintelectuales, de entregar el pensamiento reflexivo a las servidumbres de la práctica, de despreciar la teoría que busca la verdad como un fin en sí mismo.

Puede ser que hoy día Rorty suene antiintelectual y antifilosófico; pero su estilo, me parece a mí, no tiene nada que ver con el positivista; así que afirmar que el neopragmatismo radical es tan antifilosófico como el positivismo no es decir nada, o decir bastante poco, o, simplemente, no es más que lanzar una provocación. ${ }^{56}$ No ganamos nada usando "positivismo" de

${ }^{55}$ Véase R. Rorty, "La justicia como lealtad ampliada", en Pragmatismo y política.

${ }^{56}$ Curiosamente, yo diría que Haack es la que a veces suena positivista. Por ejemplo, cuando dice sobre James exactamente lo mismo que ya dijo Ayer en su famosa introducción a Pragmatism: que muchas de las afirmaciones polémicas de James sobre la verdad y la utilidad sólo se aplican a las creencias de tipo religioso (Evidencia e investigación, p. 276). Decir que sólo en los dominios de la moral y de la religión la ecuación de verdad y conveniencia, por la que 
una forma tan peyorativa; en vez de eso, deberíamos ver de nuevo las cosas en contexto y quizás contar de forma más precisa cuáles fueron las relaciones reales entre el positivismo y el pragmatismo (explicar, por ejemplo, qué le interesó a Ayer de los pragmatistas, qué puntos en común encontraron Dewey y Neurath, qué debate mantuvieron Stevenson y Dewey).

Supongo que Haack habla en broma cuando dice que conforme las tendencias reformistas del pragmatismo clásico han ido derivando hacia las radicales y antiintelectuales, "uno comienza a temer que Russell tuviera razón cuando predijo que el pragmatismo conduciría a la 'impiedad cósmica' o, en todo, caso, al fascismo" (VNP, p. 23). Semejante exageración, creo, no tiene ningún valor, excepto el de calentar innecesariamente el ambiente. ¿De verdad cree Haack que el antiintelectualismo de Rorty está promoviendo el fascismo? Quizás el antiintelectualismo de Rorty no sea la mejor opción en un país, Estados Unidos, donde el antiintelectualismo es una actitud popular políticamente nociva. Pero de eso a decir que el neopragmatismo fomenta el fascismo hay mucha distancia, ¿o no? Una cosa es que el neopragmatismo no inspire la mejor forma de política y otra muy distinta que conduzca a la barbarie.

Para Rorty, ya lo he dicho, el antiintelectualismo es una forma de fortalecer el reformismo democrático y alejarse del radicalismo político. ${ }^{57} \mathrm{Ni}$ las discusiones epistemológicas sobre la verdad o la ciencia, ni las grandes teorías filosóficas sobre la racionalidad y la democracia (como la de Habermas), ni la deconstrucción de la metafísica occidental (Derrida, De Man) sirven de mucho a la política democrática, excepto a largo plazo. "Considero a la ética y a la política — a la política real como opuesta a la política cultural- como una cuestión de lograr acomodar intereses contrapuestos y como algo para debatir en términos banales, familiares, términos que no necesitan disección filosófica y que no tienen presuposiciones filosóficas." El espíritu antifilosófico, pues, sólo es un medio práctico para despejar el

James ha sido ampliamente criticado, puede serle atribuida con justicia es profesar una típica división positivista entre lo cognitivo y lo no cognitivo que, me temo, Haack aún mantiene. Por otro lado, el punto de vista de James sobre la verdad no es, al contrario de lo que quiere Haack, independiente de la doctrina contenida en La voluntad de creer (Russell ya lo señaló, pero es comprensible que, como reformista, Haack insista en separar ambas doctrinas): las creencias infundadas también forman parte del día a día de la investigación científica y no sólo de las conductas morales y religiosas. Véase, sobre esto, el ensayo de Faerna "La razón insensata: una lectura epistemológica de 'La voluntad de creer' de James". Con todo, creo que las conclusiones que saca Faerna no son tan rortyanas como las que yo sacaría.

${ }^{57}$ Véase "Una visión pragmatista de la racionalidad y de la diferencia cultural", en R. Rorty, Pragmatismo y política. Las sociedades democráticas actuales ya han creado medios para denunciar y erradicar el sufrimiento y la injusticia; no se precisa una crítica radical, sino sólo atención a los detalles. La labor del filósofo, por tanto, no es denunciar fundamentos falsos o corruptos de esas sociedades, sino sólo contraponer sus rasgos buenos y malos. "La filosofía como ciencia, como metáfora y como política", Ensayos sobre Heidegger y otros pensadores contemporáneos, p. 45. 
camino y facilitar maneras concretas y no teóricas de acomodar intereses y satisfacer deseos. "Lo político, tal como yo lo veo, es una cuestión pragmática de reformas a corto plazo y compromisos, compromisos que deben en una sociedad democrática, ser propuestos y defendidos en términos menos esotéricos" que aquellos con los que los deconstruccionistas pretenden superar la metafísica, y también en términos menos trascendentales que aquellos con los que Habermas pretende fundamentar las instituciones democráticas. ${ }^{58}$ A largo plazo, desde luego, algunas ideas filosóficas pueden llegar a ser útiles para la política diaria; pero a corto plazo, su utilidad no reside ni en que fundamenten ni en que subviertan la política, sino como mucho en que sugieran formas concretas, provisionales e improvisadas de casar creencias, intereses y necesidades reales. Para la defensa de la democracia no tiene gran utilidad una forma hiperteórica e hiperfilosofizada de expresar convicciones políticas.

El pragmatismo ironista, pues, es antiintelectual en este solo sentido: reduce la filosofía a una reflexión "que no intenta una crítica radical de la cultura contemporánea ni intenta refundarla o remotivarla, sino que simplemente recopila recordatorios y sugiere algunas posibilidades interesantes". ${ }^{59}$ El terrible antiintelectualismo de Rorty, entendido en su contexto, sólo es una reacción contra ciertos tipos de filosofía que esperan demasiado de sí mismas, pero no una invitación al irracionalismo, como da por hecho Haack. Banalizar la filosofía no es promover el "todo vale", sino evitar falsas esperanzas o ilusiones, y promover una filosofía más vaga, más laxa, incluso más débil, pero más práctica y circunstancial.

El lema de Rorty "nos convendría debatir explícitamente los temas políticos, en vez de utilizar un lenguaje filosófico exótico" no atañe sólo a la filosofía posmoderna influida por modas francesas o a filosofías sistemáticas como la de Habermas, sino también a toda esa epistemología interdisciplinaria que, como la de Haack, trata de extraer moralejas sociales a partir de sesudas discusiones sobre el concepto de verdad o sobre el de objetividad. ${ }^{60}$ En todos los casos, viene a decir Rorty, la filosofía sólo se conecta

${ }^{58}$ Los dos textos citados están en "Notas sobre deconstrucción y pragmatismo", en C. Mouffe (comp.), Deconstrucción y pragmatismo, pp. 42-43. Véase también la p. 96.

${ }^{59}$ Introducción a Ensayos sobre Heidegger, p. 22. Véase también la ilustrativa introducción a Objetividad, relativismo y verdad, pp. 33 y s.

${ }^{60}$ Salvando algunas distancias, yo aplicaría todos los argumentos que Rorty lanza contra Habermas a muchos pragmatistas reformistas: "creo que la cuestión de la verdad no puede ser relevante para la política democrática y que los filósofos interesados en esa política tendrían que olvidarse de la verdad y ceñirse al tema de la justificación [...]; los filósofos que nos interesamos por la política democrática deberíamos dejar en paz la verdad [...] y en su lugar pasar a considerar el problema de cómo persuadir a la gente de que amplíe las dimensiones de la audiencia que considera competente [...]; creo que deberíamos conformarnos con decir que no hay ninguna tesis filosófica sobre la contingencia o la verdad que pueda contribuir de forma decisiva a favor de la política democrática" (Pragmatismo, una versión, pp. 82, 85, 111). 
de una forma indirecta con la vida social, o sea, no ofrece un conocimiento especial ni revela una dimensión más profunda o esencial de los conflictos sociales. Si uno se siente "socialdemócrata deweyano", dice Rorty, entonces puede resultar tan políticamente útil como

los poetas, los dramaturgos, los economistas y los ingenieros. Los miembros de estas distintas profesiones pueden fomentar una política social democrática reformista realizando ocasionales llamadas de atención y advertencias con respecto a determinados proyectos en ciertos momentos [...]; considera la función de la filosofía [...] como una labor continua con la de la literatura y las ciencias sociales. ${ }^{61}$

Una labor que sólo posee una utilidad política circunstancial, y no el tipo de utilidad fundamental o de relevancia trascendental que se arrogan muchas sectas filosóficas.

\section{Tradiciones, traiciones}

Unas palabras para acabar. Me parece que una tradición intelectual no se puede concebir como un cúmulo de distorsiones, o por lo menos no como un cúmulo de distorsiones destructivas y nocivas. También las hay creativas y provechosas. Haack, creo yo, no deja mucho margen para el espíritu pragmático cuando dice que la historia del pragmatismo se parece "al viejo chiste de los soldados que pasan un mensaje a lo largo de la fila: el primero le dice al segundo: 'Envíen refuerzos, vamos a avanzar'; y el penúltimo le dice al último 'Envíen dinero, vamos a bailar'" (VNP, p. 24). Concebir así la transmisión intelectual es absurdo y me temo que demasiado sencillo; un pragmatista, de hecho, podría lanzar otro chiste más ajustado a la realidad: el primer soldado le dice al segundo: "Envíen más refuerzos, vamos a avanzar", y el penúltimo le dice al último: “¿Hacia dónde tenemos que avanzar?”; o incluso: “¿Por qué tenemos que avanzar?” El eliminacionismo, asociado correctamente por Haack al neopragmatismo radical, no es un escepticismo desalentador sin más fin que la distorsión intelectual y la agitación social, sino una forma de ver qué tipos de preguntas tienen sentido en relación con los problemas que vivimos.

61 "La filosofía como ciencia, como metáfora y como política", en Ensayos sobre Heidegger, p. 45. El punto de vista de Rorty, pues, es que deberíamos ver las prácticas científicas en continuidad con el resto de las prácticas sociales, aunque lo que la mayoría de sus críticos le atribuyen es la idea de que deberíamos sustituir la ciencia por la literatura o la verdad por la ficción. Según sus críticos, Rorty dice que debemos subordinar la búsqueda de la verdad a la búsqueda de la felicidad, cuando lo que realmente dice es que no debemos separarlas (Pragmatismo, una versión, p. 48). 
Rorty dijo en otro contexto algo que, nuevamente, resulta provocativo para reformistas como Haack, sólo que esta vez lo hizo usando nada menos que las propias palabras de Dewey:

persiste la convicción de que todas las preguntas que la mente humana se ha planteado pueden ser contestadas en los términos de las alternativas que esas mismas preguntas plantean, aunque la historia nos muestre que tal idea es una alucinación. Pero, de hecho, el progreso intelectual suele acontecer por el mero abandono de preguntas junto con las alternativas que ellas dan por supuestas, un abandono que nace tanto de su vitalidad decreciente como de un cambio de los intereses más urgentes. No respondemos esas preguntas, vamos más allá de ellas. ${ }^{62}$

En relación con los problemas de los que el pragmatismo siempre ha tratado de hacerse cargo, problemas culturales, creo yo, las preguntas de la epistemología profesional tal como discurre hoy quizás tengan poco que decir, o sean algo demasiado alejado de los problemas reales que nos toca afrontar. Es comprensible, entonces, que algunos neopragmatistas viren hacia otro tipo de terrenos como las humanidades, un campo que, para bien y para mal, siempre ha sido un cesto en el que cabe todo tipo de discursos. Para estos neopragmatistas, el giro de la filosofía hacia la crítica cultural es provechoso, aunque la filosofía, como una tableta efervescente, pierda solidez y se disuelva en el vaso de las humanidades.

El pragmatismo, para concluir, se ha quedado varado en algún lugar entre (1) la epistemología pospositivista, el territorio al que Haack todavía quiere circunscribirlo, por mucho que en su crónica aluda a la dimensión política y social de esa tradición; (2) la teoría social, el territorio sobre el que Dewey más avanzó y en el que algunos representantes del neopragmatismo todavía tienen cosas que decir, y (3) las humanidades, su hogar ancestral, un territorio impreciso en el que se mezclan la filosofía, la política cultural, la historia y la crítica literaria, un territorio en el que el pragmatismo de James y Dewey se abrió paso y que Rorty intenta recuperar hoy día, aun a costa de rodearse de interlocutores y compañeros de viaje poco deseables para quienes pueblan el área profesional (1) y algo dudosos para los que habitan el área (2).

Puede ser, lo sé, que en esta respuesta a Haack me haya decantado demasiado por Rorty, pero creo que merece la pena, dado que, en la composición de Haack, Rorty es retratado injustamente como la encarnación de muchos males. Sin embargo, la versión de Haack es poco histórica y disimula el hecho de que el pragmatismo siempre se encaminó hacia donde lo lleva Rorty. Peirce contribuyó decisivamente al nacimiento del pragmatismo; pero el pragmatismo no habría sido lo que fue si no fuera por James

${ }^{62}$ Middle Works, vol. 4, p. 14, citado por Rorty en "Norteamericanismo y pragmatismo", vid supra. 
y Dewey. De la misma forma, si el neopragmatismo tiene una voz particular en la escena de la filosofía contemporánea es, para bien o para mal, gracias a radicales como Rorty.

Espero, eso sí, tener otra ocasión para explicar mis propias dudas sobre Rorty...

\section{BIBLIOGRAFÍA}

Bernstein, Richard, "American Pragmatism: The Conflict of Narratives", en H.J. Saatkamp, Rorty and Pragmatism, pp. 54-67.

Bloom, Harold, Agon, Towards a Theory of Revisionism, Oxford University Press, Oxford, 1982.

Castillo, Ramón del, "Desde un punto de vista pragmático: Quine y sus críticos", en

L. Arenas, A. Jiménez y J. Muñoz (comps.), El retorno del pragmatismo, Trotta, Madrid, 2000, pp. 239-286.

__, "¿A quién le importa la verdad? A vueltas con James y Dewey”, Ágora, Universidad de Santiago de Compostela, 2003 (en prensa).

—, "Prólogo" a W. James, Pragmatismo.

Dancy, Jonathan y Ernest Sosa (eds.), A Companion to Epistemology, Blackwell, Oxford, 1992.

Dewey, John, "El carácter práctico de la realidad" (1908), La miseria de la epistemología. Ensayos de pragmatismo, pp. 157-174.

_- Essays, Miscellany and Reconstruction in Philosophy published during 1920, The Middle Works, 1899-1924, vol. 12, 1920, ed. Jo Ann Boydston, Southern Illinois University Press, Carbondale.

__, "Existence, Value and Criticism", The Later Works 1925-1953, vol. 1, 1925, Southern Illinois University Press, Carbondale/Edwardsville, 1988, pp. 295326.

__ La miseria de la epistemología. Ensayos de pragmatismo, trad. Ángel Faerna, Biblioteca Nueva, Madrid, 2000.

—_ La reconstrucción de la filosofía, trad. Amando Lázaro Ríos, Aguilar, Buenos Aires, 1970.

__, "Short Catechism Concerning Truth", The Middle Works, vol. 6, Southern Illinois University Press, Carbondale, 1988, pp. 3-11.

—., "Theory of Valuation", The Later Works, vol. 13, pp. 189-251.

Esteban Cloquell, José Miguel, La crítica pragmatista de la cultura, Universidad Nacional de Costa Rica, Heredia, 2001.

Faerna, Ángel, "Introducción” a J. Dewey, La miseria de la epistemología. Ensayos de pragmatismo, pp. 9-24.

—_ 'La razón insensata: una lectura epistemológica de 'La voluntad de creer' de James", Ágora, Santiago de Compostela, 2003 (en prensa).

Feyerabend, Paul K., Ambigüedad y armonía, introd. Fernando Broncano, trad. Antoni Beltrán y José Romo, Paidós, Barcelona, 1996.

__, La ciencia en una sociedad libre, trad. Alberto Elena, Siglo XXI, México, 1982. 
Fish, Stanley, "Truth and Toilets: Pragmatism and the Practices of Life", en Morris Dikstein, The Revival of Pragmatism, New Essays on Social Thought, Law and Culture, Duke University Press, Durham, 1998, pp. 298-307.

Geneyro, J.C., La democracia inquieta, E. Durkheim y J. Dewey, Anthropos, Madrid, 1991.

Goodman, Nelson, Maneras de hacer mundos, trad. Carlos Thiebaut, Visor, Madrid, 1990.

Haack, Susan, "Can James's Theory of Truth be Made More Satisfactory?", Transactions of the Charles S. Peirce Society, 1984, vol. XX, no. 3, pp. 269-276.

_- Evidence and Inquiry: Towards Reconstruction in Epistemology, Blackwell Oxford, 1993 [versión en castellano: Evidencia e investigación, trad. María Ángeles Martínez García, Tecnos, Madrid, 1997].

—, Manifesto of a Passionate Moderate, The University of Chicago Press, Chicago, 1998.

_-, "Pragmatism", A Companion to Epistemology, Blackwell, Oxford, 1992, pp. 351-357.

Hook, Sidney, John Dewey: semblanza intelectual, trad. Luis Arenas, Paidós, Barcelona, 2001.

James, William, La voluntad de creer, trad. Santos Rubiano, Daniel Jorro Editor, Madrid, 1922.

__ Pragmatismo, un viejo nombre para nuevas formas de pensar, trad. Ramón del Castillo, Alianza, Madrid, 2000.

—, The Meaning of Truth. A Sequel to Pragmatism, Harvard University Press, Cambridge, Mass., 1970.

—_, "Los moralistas y la vida moral", La voluntad de creer, pp. 177-204.

Mouffe, Chantal (comp.), Deconstrucción y pragmatismo, trad. Marcos Mayer e Inés Pousadela, Paidós, Barcelona, 1998.

Putnam, Hilary, La herencia del pragmatismo, trad. Manuel Liz y Margarita Vázquez, Paidós, Barcelona, 1997.

—- Reason, Truth and History, Cambridge University Press, Cambridge, Mass., 1981. [Versión en castellano: Razón, verdad e historia, trad. José Miguel Esteban Cloquell, Tecnos, Madrid, 1988.]

_- Words and Life, Harvard University Press, Cambridge, Mass., 1994.

Quine, W.V.O., "Respuesta a M.J. Cresswell", Teorías y cosas, trad. Antonio Zirión, Universidad Nacional Autónoma de México, México, 1986, pp. 214-216.

Rorty, Richard, Consecuencias del pragmatismo, trad. José Miguel Esteban Cloquell, Madrid, Tecnos, 1996.

—_ Contingencia, ironía y solidaridad, trad. Alfredo Eduardo Sinnot, Paidós, Barcelona, 1991.

__ Ensayos sobre Heidegger y otros pensadores contemporáneos, trad. Jorge Vigil Rubio, Paidós, Barcelona, 1993.

__ , "El pragmatismo, Davidson y la verdad", en Objetividad, relativismo y verdad, pp. 173-206. Conviene leer el original inglés en Objectivity, Relativism and Truth, Cambridge University Press, Cambridge, 1991.

_- Forjar nuestro país. El pensamiento de izquierdas en los Estados Unidos del siglo XX, trad. Ramón del Castillo, Paidós, Barcelona, 1999. 
Rorty, Richard, La filosofía y el espejo de la naturaleza, trad. Jesús Fernández Zulaica, Cátedra, Madrid, 1979.

__ , "La verdad sin correspondencia", ¿Esperanza o conocimiento? Una introducción al pragmatismo, trad. Eduardo Rabossi, Fondo de Cultura Económica, México, 1997, pp. 7-42.

__ "Norteamericanismo y pragmatismo", Isegoría (El nuevo pragmatismo), trad. Carlos Thiebaut, no. 8, 1993, pp. 5-25.

_- "Notas sobre deconstrucción y pragmatismo", en C. Mouffe (comp.), Deconstrucción y pragmatismo, pp. 35-44.

—_, Objetividad, relativismo y verdad, trad. Jorge Vigil Rubio, Paidós, Barcelona, 1996.

_- Philosophy and Social Hope, Penguin, Londres, 1999.

_- "Philosophy and the Future", en H.J. Saatkamp (comp.), Rorty and Pragmatism, pp. 197-205.

—_, "Pragmatism, Davidson and Truth", Objectivity, Relativism and Truth, Cambridge University Press, Cambridge, 1991, pp. 126-150.

_- Pragmatismo, una versión: antiautoritarismo en epistemología y ética, trad. Joan Verges Gifra, Ariel, Barcelona, 2000.

—_, Pragmatismo y política, trad. Rafael del Águila, Paidós, Barcelona, 1998.

__, "Solidaridad u objetividad", Objetividad, relativismo y verdad, pp. 39-56.

— Verdad y progreso, trad. Á.M. Faerna, Paidós, Barcelona, 2000.

Ross, Dorothy, The Origins of American Social Science, Cambridge University Press, Cambridge, 1991.

Saatkamp, H.J., Rorty and Pragmatism, Vanderbilt University Press, Nashville, 1995. Torre, Antonio de, "El efecto Rorty", Anábasis. Revista bibliográfica de filosofía, año 7, no. 3/4, verano/otoño, 2000, pp. 185-196.

Recibido el 23 de mayo de 2002; aceptado el 23 de julio de 2002 